\title{
A Review of Using Conductive Composite Materials in Solving Lightening Strike and Ice Accumulation Problems in Aviation
}

\author{
Belal Alemour¹, Omar Badran², Mohd Roshdi Hassan
}

\author{
Alemour B (iD https://orcid.org/0000-0002-7346-934X \\ Bradan 0 (iD https://orcid.org/0000-0002-6984-5015 \\ Hassan MR (iD https://orcid.org/0000-0002-5167-3075
}

\section{How to cite}

Alemour B, Bradan O, Hassan MR (2019) A Review of Using Conductive Composite Materials in Solving Lightening Strike and Ice Accumulation Problems in Aviation. J Aerosp Technol Manag, 11: e1919. https://doi.org/10.5028/jatm.v11.1022.

\begin{abstract}
There are many problems facing aircraft in the air during flight, such as lightning strikes and ice accumulation on aircraft surfaces. These problems usually reduce aircraft efficiency and lead to serious accidents and fatalities. However, the current protection systems used to solve these problems of aircraft represent excessive energy usage, a hazard to the environment, and they are generally bulky, heavy and costly. Therefore, there are new conductive composites containing an embedded layer of conductive fibers such as graphene and carbon nanotube designed to carry lightning currents, in addition to that, there is a new deicing heater element made of graphene nanoribbons films to be used in ice protection systems. This paper presents a review of some problems facing aircraft in the air, such as lightning and ice accumulation on the surfaces of the aircraft and the significant efforts that have been exerted to address and solve these issues. Also, this paper reviews the contribution of composite materials in reducing the weight of the aircraft and fuel consumption as well as increasing the efficiency of aircraft. This paper also will review the conductive composite materials and its application for aviation, in addition to their contribution to solving the most important problems in aviation.
\end{abstract}

KEYWORDS: Carbon, Composite materials, Electrical resistivity, Composites, Electronic properties, Nanocomposites.

\section{INTRODUCTION}

Engineering materials are divided into metals, polymers, ceramics, and composite materials. These materials have been used by peoples from ancient times (BC) to the present time, as is seen in Fig. 1. The composite materials are made to replace traditional materials such as metals, ceramics, and polymers because they have superior properties that outperformed traditional materials such as the lightweight, corrosion resistant, high strength, and stiffness, withstand high temperature, and easily formed in the manufacturing process. Composite materials consist of two or more substances, combined together without melting into each other, to form a new material with new properties that differ from the properties of the constituent materials. One of the substances is called the matrix and this contains the other materials, while the other substance is called the reinforcement that is immersed in the matrix. The matrix material is usually a polymer such as epoxy, while the reinforcing material is a fiber such as carbon fiber and glass fiber (Chamis 1989; Soutis 2005; Andersson et al.; Mangalgiri 1999). 
In aircrafts applications, the weight of structures is a critical parameter in determining its performance. The need for lowest possible structural weight led to the development of high-performance composites using carbon fibers and epoxy resins. Their use has been gradually increasing over the last few years, leading to a decline in the use of metallic materials. Composite materials have low weight and higher values of strength and stiffness than conventional aircraft materials like aluminum, titanium, and steel, in addition to its corrosion resistance. Aircrafts are exposed to some important problems in the air that cause serious accidents or decrease their performance, which make the flight unsafe. One of these problems is the lightning strikes which hit the aircraft's surfaces such as fuselage, where a high current is generated, which, if not dissipated, will enter the airplane and cause dangerous fires. Another problem facing the aircraft in the air is ice accumulation on the surfaces of the aircraft such as wings, which might change the shape of the airflow over the surface causing an increase of the drag force that leads to deterioration of aircraft performance. Therefore, it was necessary to address these problems over the decades and find solutions to them, as the composite material currently used in the manufacture of aircraft structures have a poor electrical conductivity, which unable to dissipate the electrical current coming from lightning strikes or work as a heating element to deice the surfaces of the aircraft. The current solutions used in aviation have metals such as copper and aluminum, which have several problems such as heaviness, corrosion of the composite material used in aircraft structures, and high maintenance cost. It is necessary to find another solution to these problems instead of the current technology used, therefore, new composite materials have been developed to solve the problems of lightning strike and ice accumulation. One of these developed materials is conductive composite materials, which have high electrical conductivity, lightweight, low maintenance cost, and resistance to corrosion (Werfelman 2007; Yang et al. 2012; Nayak 2014).

This paper presents a review of composite materials used in aviation and their use in the construction of aircraft's body, in addition to its contribution to reducing the weight of the aircraft and fuel consumption as well as increasing the efficiency of aircraft. Some problems facing aircraft in the air, such as lightning strike and ice accumulation are reviewed, and the current significant efforts that have been exerted to address and solve these issues are investigated. This paper will also review the conductive composite materials and its application in aviation, in addition to their contribution to solving the most important problems in aviation.

Evolution of engineering materials

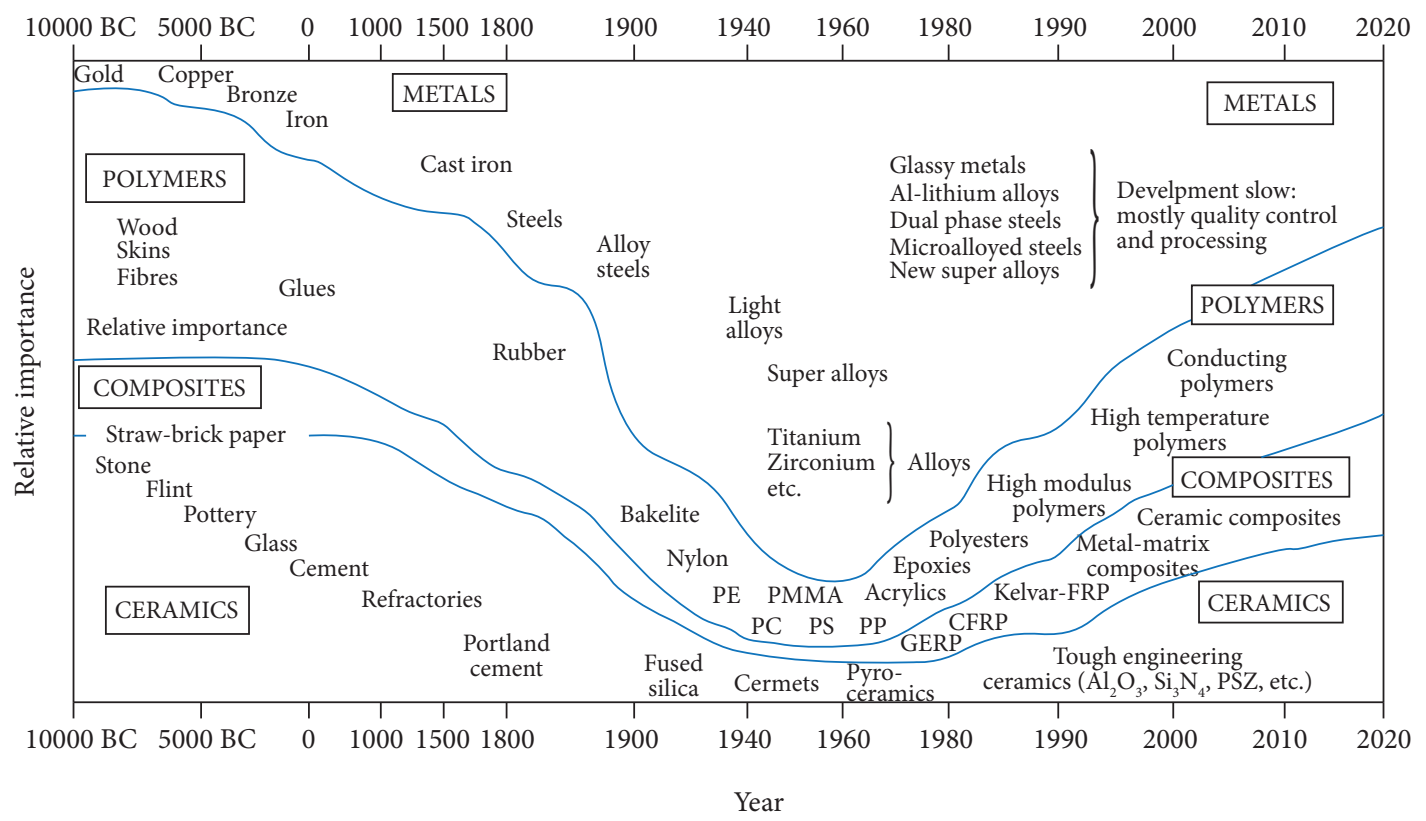

Figure 1. The importance of the four classes of materials (ceramics, composites, polymers, and metals) in engineering as a function of time. The timescale is nonlinear (White 2011). 


\section{CONDUCTIVE COMPOSITE MATERIAL}

Conductive composites include any composite having electrical conductivity; a conductive composite commonly consists of dispersing certain volume fractions of conductive filler in a nonconductive (or less conductive) matrix, which exhibit a large scale of electrical conductivities needed for different applications. Lightweight, stable, conductive composite materials are useful in many applications such as battery components, electrodes, electromagnetic interference shields, circuitry components, and aviation (Chung 2010; Kaur 2015; Tsekmes et al. 2013). In order to composite materials be used for conductive applications, the materials should have an electrical conductivity in the range of $10^{-12}$ and $10^{-8} \mathrm{~S} / \mathrm{cm}$ for ESD applications, $10^{-8}$ and $10^{-2} \mathrm{~S} / \mathrm{cm} \mathrm{for}^{-}$ moderately conductive applications, and $10^{-2} \mathrm{~S} / \mathrm{cm}$ and higher for shielding applications. The electrical conductivity of a composite depends on the filler volume fraction (see Fig. 2), when the filler amount in the composite is increased, the filler particles begin to form a continuous path which makes the free electrons in the composite to travel easily by contacting each other, and eventually the electrical conductivity will be increased to higher levels, as shown in Fig. 3. The formation of this conductive network is based on the principles of percolation theory (Fiske et al. 1997; McCullough 2000; Clough and Sylwester 1989).

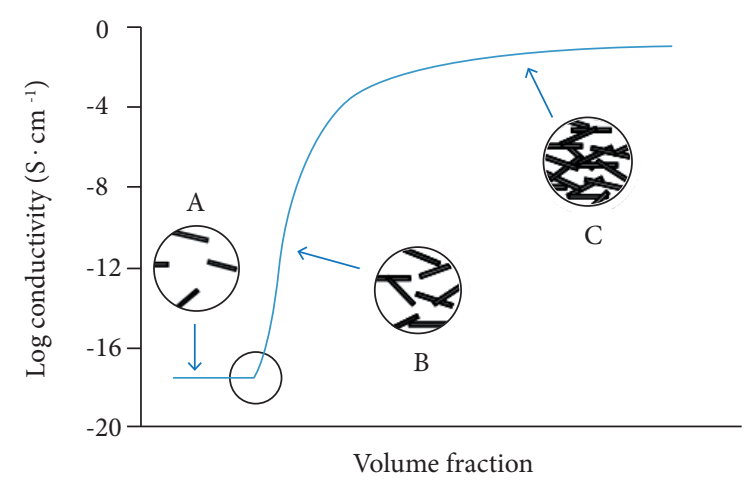

Figure 2. The dependence of electrical conductivity on the filler content (McCullough 2000).

(a)

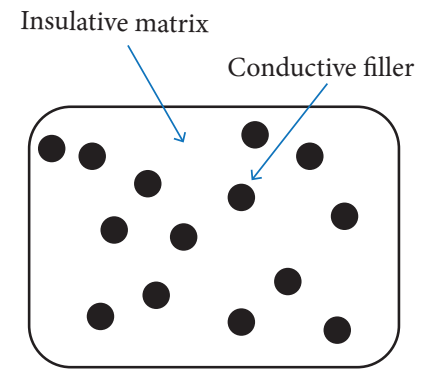

(b)

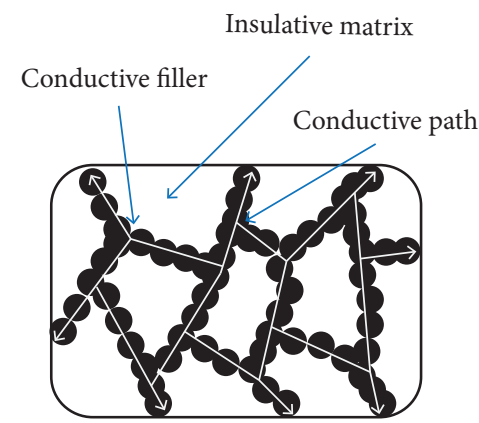

Figure 3. Filler distribution in polymer composite (a) at low content, (b) conductive path at high enough content (Tsekmes et al. 2013).

When the content of the conductive filler increases gradually, the composite material reaches the percolation threshold. Any further increase in the content of the conductive filler in the material after this threshold will lead to a many orders of magnitudes increase of the electrical conductivity value of the composite material, which becomes a conductive composite material, as shown in Fig. 4. This behavior occurs because the conductive filler formed a conducting path through the dielectric matrix material; 
this conductive path is formed when the conductor filler content is higher than the percolation threshold (Mamunya et al. 1996; Peters 2013; Ashby and Johnson 2013).

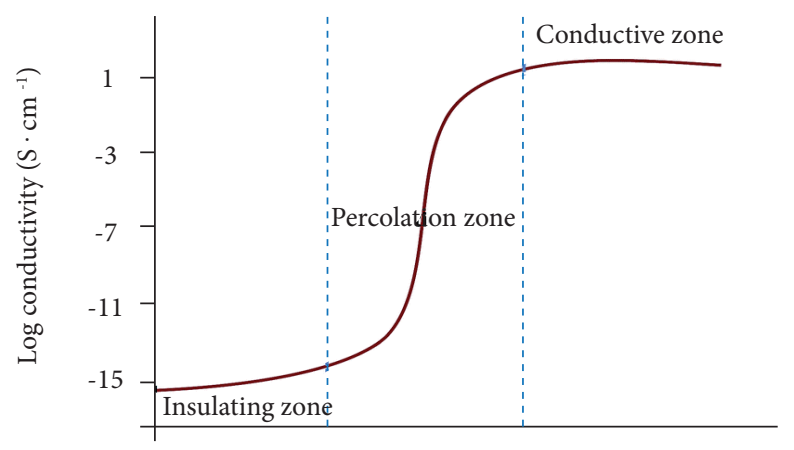

Filler concentration (\%)

Figure 4. The percolation zone of conductive fillers reinforced polymer composites (Ruschau et al. 1992).

By adding conductive fillers to the polymers, materials can be produced and designed with certain properties that are suitable for each application (see Fig. 5). The electrical conductivity value of polymers commonly can be between 10-14 and 10-17. The electrical conductivity values of other materials are 102 for carbon black, 103 for Polyacrylonitrile, 104 for carbon fibers, 105 for graphite, and 106 for metals such as aluminum and copper. All electrical conductivity values are given in S/cm. The composite materials must have an electrical conductivity in the range of 10-12 and 10-2 S/cm to be used for conductive applications, such as electrostatic dissipation and shielding (Campbell 2010; Ruschau et al. 1992).

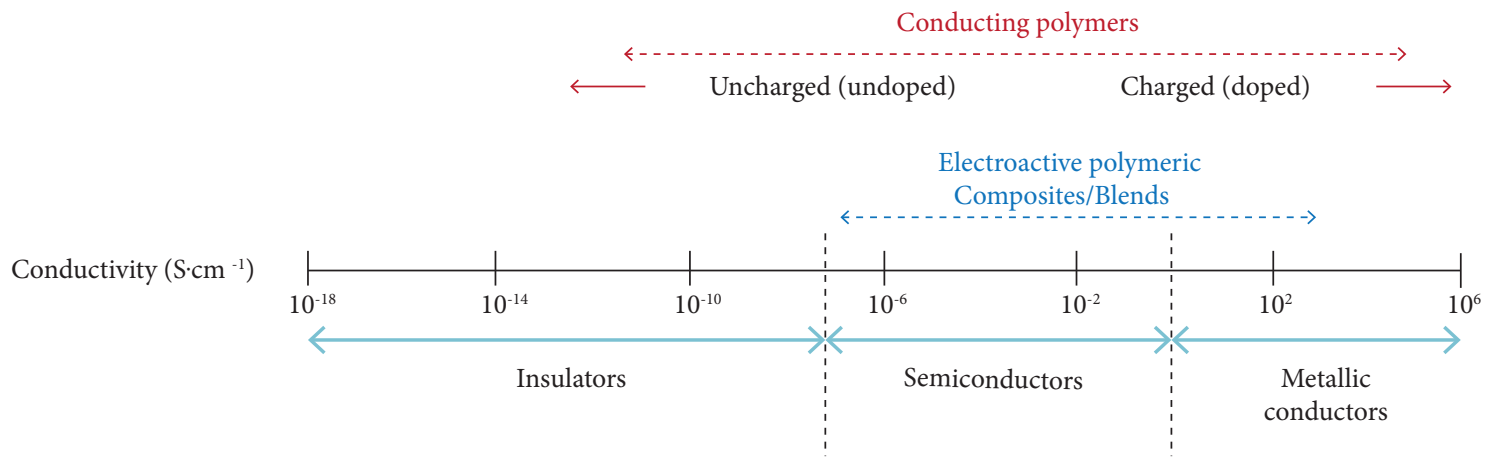

Figure 5. Conductivity range of conducting polymers and conductive polymer composites (Campbell 2010; Ruschau et al. 1992).

The electrical conductivity of conductive composites depends on filler type, shape, size, and filler dispersion and distribution in the composite. The properties of the filler play a significant role in determining the conductivity of the composite. Carbon, when used as a filler, comes in many different forms, from small carbon particles to graphite fibers, and the conductivity of each is different. The value for filler conductivity will be the upper limit for the electrical conductivity of the composite. Other filler properties, such as particle size, can also have an effect on the electrical conductivity. It has been shown that for spherical particles, the smaller particle size will lower the percolation threshold. It has also been shown that an aspect ratio (ratio of length 
to diameter, $1 / \mathrm{d}$ ) greater than one, as well as a broader range of aspect ratios will lower the percolation threshold. The method by which the composites are made and subsequently molded into parts has also an effect on electrical conductivity, where the filler orientation has an effect on the electrical conductivity of composites (Göktürk et al. 1993; Kalaitzidou et al. 2007; Yi and Choi 1999; Advani and Tucker III 1987). Extrusion and injection molding of a composite can align fillers that have an aspect ratio greater than one in a certain direction due to the flow through the nozzle of the different machines and the mold. This alignment will produce anisotropic conductivity within the sample, meaning that conductivity will be greater in one direction over another. The surface properties of the filler and polymer also have a significant effect on the conductivity and the percolation threshold of the composite. The surface free energies of the filler and the matrix will influence the interaction between two materials, in general, a smaller difference between the surface energy of the filler and polymer is desirable to obtain high composite electrical conductivity (Nagata et al. 1998; Yin et al. 1989).

\section{COMPOSITE MATERIALS IN THE AVIATION}

Metals have been used in aircraft manufacturing for decades. For example, four decades ago, aluminum was the dominant material in the aircraft industry, because it has many advantages such as lightweight, price and resistance to corrosion. Steel is also used in the aircraft industry, but at a much lower rate than aluminum, it has a higher value of tensile strength and elasticity, therefore, steel is used in the manufacturing of parts that need more strength in the aircrafts such as landing gear. In the 1970s, Titanium was used to make alloys with other metals, such as aluminum and nickel, to be used in the aircraft industry. Titanium has many advantages such as lightweight, high strength, and corrosion resistance. Nickel alloys are designed to resist the heat, therefore, they were used in the manufacturing of parts to withstand high temperatures. Recently, Titanium aluminide (TiAl) has been used instead of nickel alloys in the aircraft, because it weighs less than half the weight of nickel, TiAl also maintains tensile strength and corrosion resistance at high temperatures, in addition to that, they are easily formed in manufacturing. Lithium also was added to aluminum to make Aluminium-lithium alloy (Al-Li). Al-Li has many properties including low weight, low density, high tensile strength and corrosion resistance, therefore Al-Li is used as a catalyst in aircraft (Mallick 2007; Roeseler et al. 2007; Fan and Njuguna 2016; Renton et al. 2004; Kirby and Mavris 2001).

Metals are heavy, costly, need expensive maintenance, and prone to corrosion. Therefore, aircraft manufacturers recently turned to using composite due to its distinctive advantages. For example, composite materials have lightweight, which leads to improvement of fuel efficiency and performance of the aircraft, in addition to reduction of operating costs in the long run. Composites also provide structural strength comparable to metallic alloys (stronger than aluminum or steel). Therefore, Composite materials can be manufactured to be light and have high strength in a specific direction to be suitable in many applications. Composite materials can resist damage and fatigue; where it can absorb impacts caused by external sudden force. Composites also may be molded into complex shapes more easily than other materials. This allows the designers to create nearly any shape or form freely. In addition to that, composites can resist the corrosion caused by the weather and the harsh chemicals. Composites also have a poor conduction of heat and electricity, making them very good insulators for applications where insulation is necessary. These excellent properties made them appropriate for use in many applications in the aircraft industry. The composites replaced metals for most aircraft applications, because manufacturing methods that produce composites in the aviation industry have progressed from purely a manual fabrication to highly automated fabrication using computer controlled machinery for laying up prepreg material (Nayak 2014; Sardiwal et al. 2014). Composites were developed in the 1960s for their weight savings over aluminum parts. The large aircrafts are designed using composites in the fuselage and wing structures. Weight savings due to the use of composite materials in aerospace applications generally range from 15\% to 25\% (Du 2007; Mouritz et al. 2001; Zimmerli et al. 2010).

Common composite materials used on airplanes include fiberglass, carbon fiber, and fiber-reinforced matrix systems or any combination of these. Glass fiber is one of the composite materials used in the manufacture of aircraft since the 1950s, it was used in the manufacture of a Boeing 707 structure, with percentage of $2 \%$. The commercial aircraft depends on the composite materials to decrease the weight and fuel consumption. The Boeing 787 will be the first commercial aircraft in which major structural 
elements are made of composite materials rather than aluminum alloys. Figure 6 shows the materials used in the structure of Boeing's 787 body. Modern aircrafts, such as the Boeing 787 Dreamliner, are comprised of more than $50 \%$ carbon fiber composite. Each generation of new aircraft built by Boeing had an increased percentage of composite material usage; the highest being $50 \%$ composite used in the yet-to-be-released 787 Dreamliner. The weight of aircraft components made of composite materials is reduced by approximately 20\%, such as in the case of the 787 Dreamliner (Lubin 2013; Dutton et al. 2004; Gay and Hoa 2007; Zhao 2003). Airbus Company also used composites in primary airplane structures in the early 1980s. In the late 1990s, the company constructed the first carbon fiber keel beam for a large commercial airplane, the A340; composites are used throughout the new A380 (Brick 1988).

With the increased risks facing the aircraft in the air, such as lightning strike and ice accumulation, which leads to a significant decrease in its performance, it was necessary to find a new conductive composite material to solve these problems. The composite material currently used in the manufacture of aircraft structures does not conduct electricity well; therefore, they are subjected to repeated destruction by weather conditions. By the discovery and development of nano-sized reinforcements, carbon nanotubes (CNTs), nanofibers and graphene are considered as key elements of the next-generation reinforced composites. With the incorporation of these nano-reinforcements into polymeric matrices, not only the mechanical reinforcement but other key properties, as electrical and thermal conductivity, can be enhanced without additional fillers. Therefore, the use of these conductive composites in the aircraft industry will solve these problems effectively (Katunin et al. 2017; Rosato 2013).

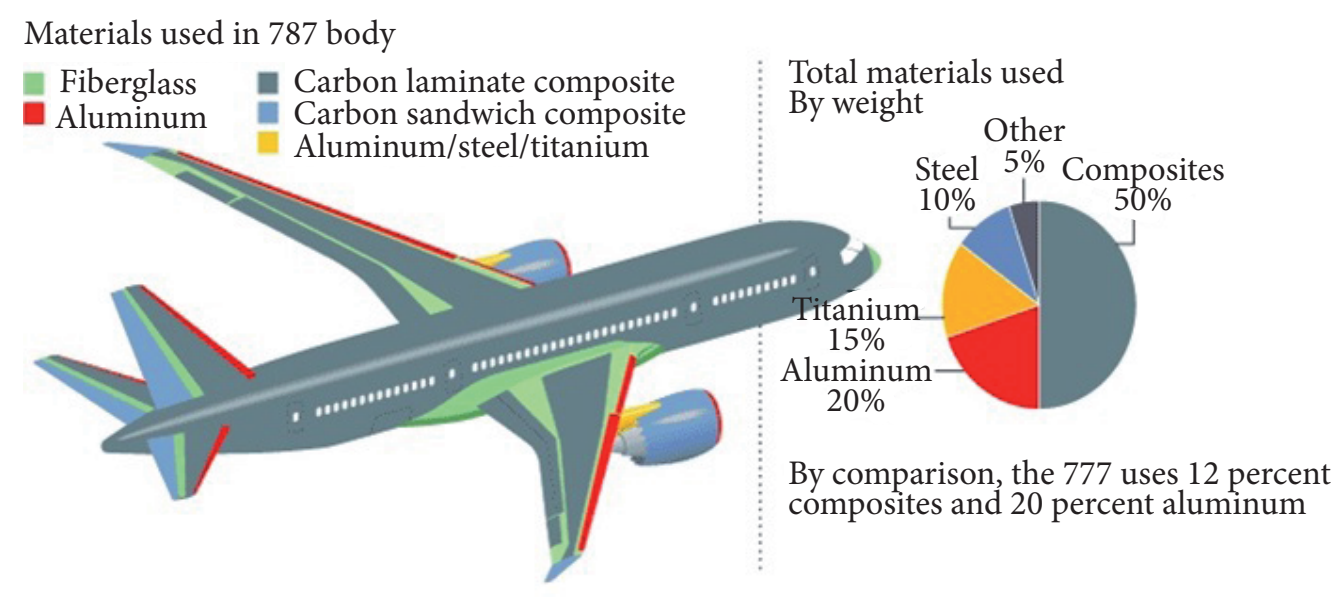

Figure 6. Usage of various materials in the Boeing 787 Dreamliner (Katunin et al. 2017; Rosato 2013).

\section{USING CONDUCTIVE COMPOSITE MATERIALS TO ENHANCE THE LIGHTNING STRIKE PROTECTION}

There are many problems facing aircraft in the air, such as lightning strikes. When the lightning strikes the aircraft, it causes serious damage to the skin of aircraft, which needs direct maintenance, delaying the aircraft and keeping it out of service for a period of time. Lightning strike can affect airplanes directly and sometimes it causes sparking that would present a danger of ignition of materials inside the aircraft skin, as shown in Fig. 7. When the lightning strikes the structure of aircraft, there are up to 200,000 amps of electrical current seeking the path of least resistance. If the aircraft structure is not protected enough, this current may cause severe problems such as vaporizing metal control cables, weld hinges on control surfaces and exploding the fuel vapors within fuel tanks if current arcs through gaps around fasteners. These direct effects also include vaporization of resin in the immediate strike area, with possible burn-through of the laminate. Indirect effects occur when magnetic fields and electrical potential differences in the structure induce transient voltages, which can damage and even destroy onboard electronics that 
have not been shielded or lightning protected (Hartman et al. 2006; Goraj 2004). The amount and type of damage an airplane experiences when struck by lightning can vary greatly, depending on factors such as the energy level of the strike, the attachment and exit locations, and the duration of the strike.

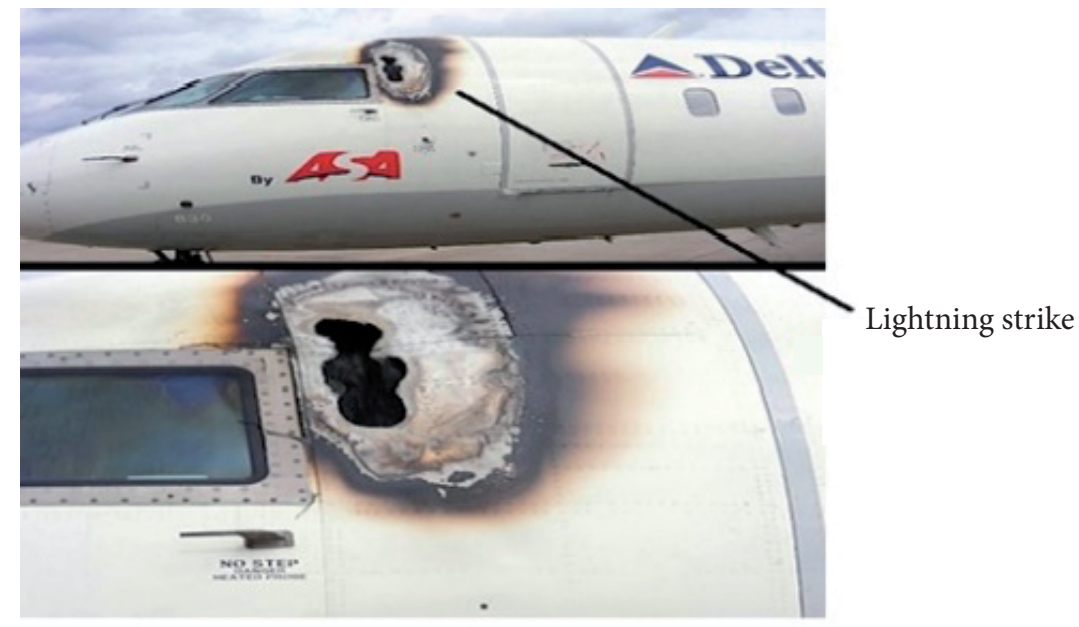

Figure 7. Lightning strike effects (Goraj 2004).

Composite materials have allowed engineers to overcome difficulties and now they are frequently used in the aircraft industry. They are five times lighter and seven times stronger than aluminum. The implementation of major aircraft structures is fabricated from carbon-fiber-reinforced plastic (CFRP) materials. Carbon fiber reinforced epoxy composites (CFRPs) are important to the aircraft industry due to its lightweight and high structural strength and stiffness, when compared to metal alloys. The usage of such materials in the manufacturing of aircraft structure will reduce fuel consumption, improve efficiency and reduce direct operating costs of aircraft; therefore, they are important to the aviation industry (Rachidi et al. 2008; Chemartin et al. 2012; Bakis et al. 2002; Ku et al. 2011). On the other hand, the carbon fiber epoxy composite has poor electrical conductivity, hence they are prone to damage from the lightning strike, and as result they need high-cost maintenance (Sweers et al. 2012). Therefore, there is a need to improve the electrical conductivity of carbon fiber epoxy composite in order to withstand high electrical currents coming from lightning strikes. Lightning strike protection systems must provide a continuous conductive path of low resistance over the entire aircraft exterior, where the current will travel through the conductive exterior skin and the structures of the aircraft and exit off some other extremity without any problem, as shown in Fig. 8 (Goraj 2004).

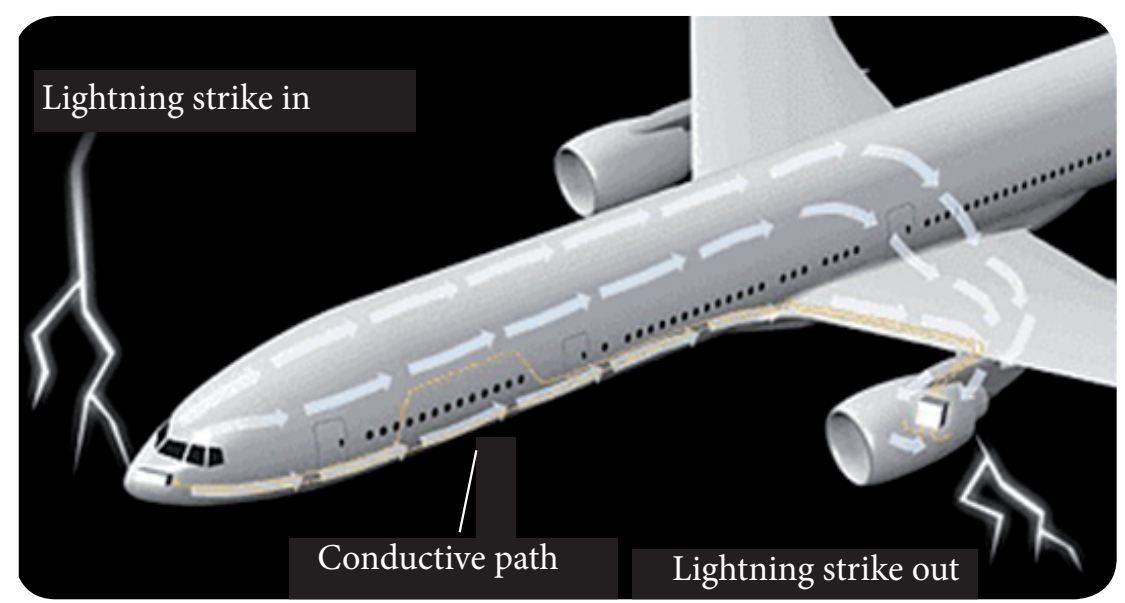

Figure 8. The continuous conductive path of low resistance over the entire aircraft exterior (Goraj 2004). 
The aircraft companies are dealing with the issue of a lightning strike by finding efficient methods to enhance lightning strike protection on the composite parts so that damages are reduced or eliminated. For example, Boeing and Airbus Companies developed lightning strike protection systems that use a metal mesh of aluminum or copper attached to the outer surface of the composite parts, in order to increase the electrical conductivity of the aircraft's structure, as shown in Fig. 9. Manufacturers begin with the main shell of carbon fiber that forms the fuselage and coat it with an extremely thin corrosion-resistant layer of fiberglass, then, at the top, they attach the aluminum or copper mesh. The metal mesh needs resin, adhesive or surface film to remain attached to the composite substructure (Gagné and Therriault 2014; Ashrafi 2010). Dexmet (Supplier Company of metal mesh) has come up with a lightning strike protection for composites with this metal mesh to resist damage to the aircraft skin. A Boeing 787 used a thin metal mesh in the outer layers of the composite fuselage and wings to provide conductivity to quickly dissipate and route charge overboard and shield onboard electronics, as shown in Fig. 10. These metal meshes added to LSP increase the overall weight

(a)

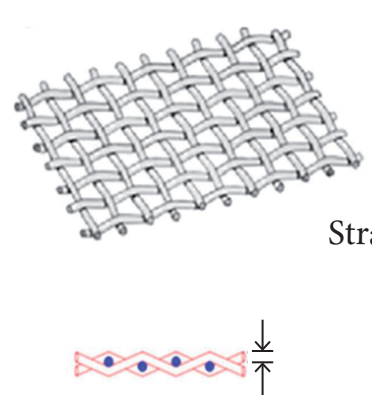

Wire diameter

Strand width
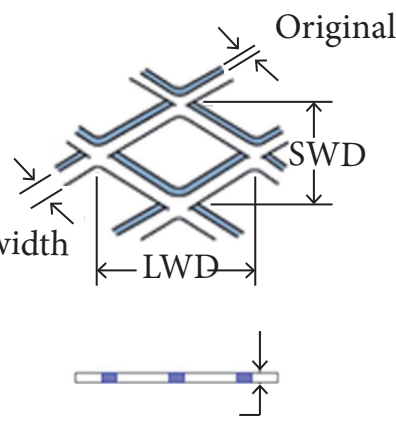

Metal thickness (b)

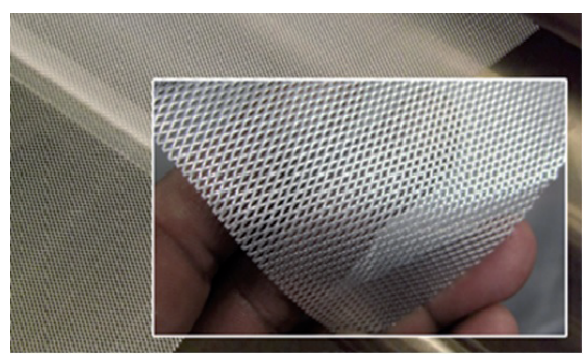

Figure 9. Metal mesh used in lighting strike protection systems in the aircrafts:

(a) woven mesh; (b) non-woven mesh (Welch 2007, Gardner 2006).

Copper sheet for lightining protection

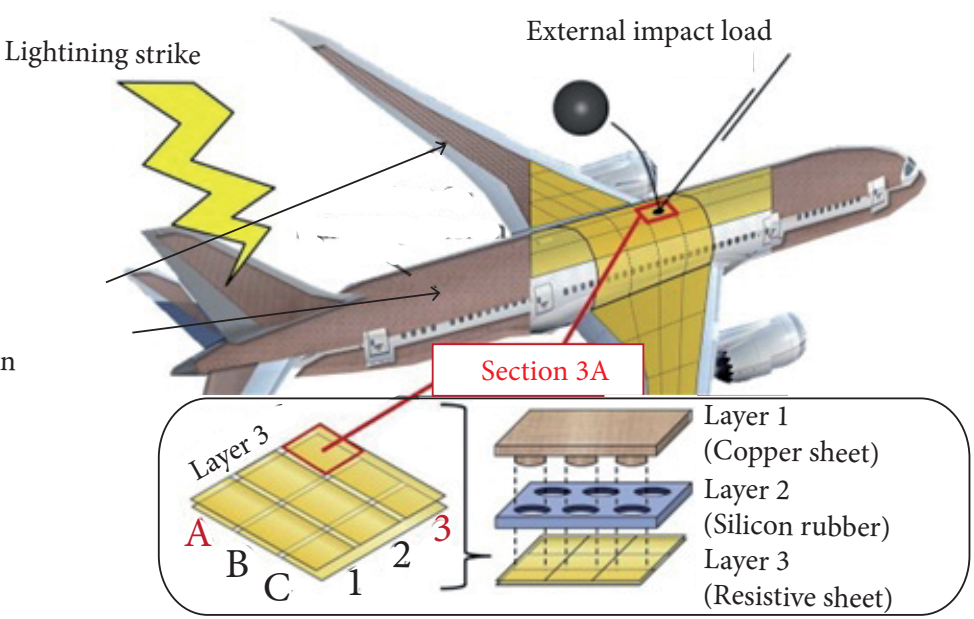

Figure 10. Distribution of copper sheets on aircraft surfaces for lightening protection (Gibson 2010; Al-Saleh and Sundararaj 2009). 
of the aircraft and this extra weight reduces fuel savings of the composite parts. The weight of metal mesh must be decreased, by increasing the "open area" of the mesh geometry and/or by decreasing the thickness of the mesh (Gibson 2010; Al-Saleh and Sundararaj 2009).

There are two types of metal meshes: a woven mesh and a non-woven mesh. A woven mesh (Fig. 9a) is made of strands of metal woven in a pattern, to ensure electrical conductivity. Woven mesh results in a heavier layer. A non-woven mesh (Fig. 9b) can be produced from nearly pure metals for maximum electrical conductivity. Compared to a woven wire mesh, a non-woven mesh can be flattened to decrease the thickness of the expanded metal to the original foil thickness, which will reduce the volume and weight of resin needed to fill the mesh, and will also produce a smoother surface on the composite. A metallic mesh can transmit $200 \mathrm{kA}$ of current if it has enough mass and electrical conductivity. Aerosystems company tested different types of panels (with or without aluminum and copper meshes) used for LSP solutions. The results showed that unprotected panels struck with lightning, resulting in a large damage area, while protected panels with aluminum mesh had a small damage area (Welch 2007; Gardner 2006).

Table 1 lists high electrical conductive metals as promising options for LSP. Using them for LSP depends on the specific electrical conductivity value, which is defined as the ratio of electrical conductivity value over density. Low specific electrical conductivity represents a poor choice for LSP because more weight will be added to the aircraft. Silver is considered the most conductive metal, but it is heavier and more expensive compared to copper or aluminum. Aluminum and copper are used nowadays in the aviation industry due to their high specific electrical conductivities, their low prices, and their ability to dissipate the lightning strikes quickly. Carbon-based materials, as listed in Table 1, are found to be interesting materials to replace or enhance the electrical conductivity of the current metallic mesh technology. Other metals are used besides aluminum and copper, such as nickel, phosphor and bronze. However, this extra weight will cause counterbalance of the weight saving provided by composite materials (Gagné and Therriault 2014; Gammon and Falcone 2003; Baur and Silverman 2007).

Table 1. Electrical conductivity and density of metal and carbon materials

(Gagné and Therriault 2014; Gammon and Falcone 2003; Baur and Silverman 2007).

\begin{tabular}{|c|c|c|c|}
\hline Material & Density $\left[\mathbf{g} / \mathbf{c m}^{3}\right]$ & Electrical conductivity $[\mathbf{S} / \mathbf{m}] \times \mathbf{1 0}^{\mathbf{6}}$ & Specific electrical conductivity \\
\hline Aluminum & 2.69 & 38.2 & 14 \\
\hline Copper & 8.93 & 59.8 & 7 \\
\hline Gold & 19.3 & 42.6 & 2 \\
\hline Iron & 7.87 & 10.3 & 1 \\
\hline Nickel & 8.9 & 14.6 & 2 \\
\hline Silver & 10.49 & 68 & 6 \\
\hline Carbon nanotube & & Carbon materials & 2 \\
\hline Graphene & 1.4 & 3.33 & 333 \\
\hline Graphite & 0.3 & 100 & 0 \\
\hline
\end{tabular}

Some companies developed another lightning strike protection solution that includes metal fibers which consist of a network of a certain metal (such as nickel) coated carbon fibers connected to each other. It was observed that there is no structural damage or delamination of underlying panels. For example, Hexcel Company used electrically and thermally conductive aluminized E-glass structural fabric for direct lightning strike protection in different important regions on the aircraft, which provides electromagnetic shielding. Metallic nanowire nanocomposites are another solution for lightning strike protection, nanowires could be aluminum, copper, silver, gold, and nickel because these materials have high electrical conductivity (Gagné and Therriault 2014; Cho and Huh 2009). These metallic nanowires can be used as nanofiller for multifunctional polymer nanocomposites. On the other hand, the experiments of Vander Voort (2004) show that they are not as efficient as metal meshes because their electrical conductivities (to the order of $104 \mathrm{~S} / \mathrm{m}$ ) are smaller than bulk 
conductivities (to the order of $106 \mathrm{~S} / \mathrm{m}$ ). However, nanowires could be used to make the adhesive films/resins conductive. They could also be used to reduce damage to the epoxy by providing a conductive path from one section of the metal mesh to the other and reduce arcing. Gou et al. (2010) tested a new LSP solution, a carbon nanofiber paper (CNFP) with nickel nanowires embedded in the resin to bridge carbon nanofibers (CNFs) together. The results showed that CNFP was more conductive, better capacity to resist lightning strikes, and with a smaller resulting damaged area from tests.

Scientists also discovered the use of aluminum in lightning protection systems has several problems; when aluminum contacts CFRP laminate, galvanic corrosion is occurring. Copper mesh is therefore used instead of aluminum to avoid galvanic corrosion, but copper has a weight higher than aluminum by three times. In addition to that, previous experiments showed that thin metal mesh can be vaporized by high current lightning strikes. Also, moisture and environmental species can cause corrosion of the metallic foils or metal meshes, thereby reducing its electrical conductivity and ability to perform its protective function (Gagné and Therriault 2014; Morgan 2013; Suzuki et al. 2014; Hale 2006). Researchers have investigated new multifunctional approaches, such as conductive paint and low-resistance structural laminate. These conductive composite materials have high electrical conductivity and can be attached to the aircraft's structure to protect them from lightning strike (Gagné and Therriault 2014; Hsieh et al. 2018). These conductive composites contain an embedded layer of conductive fillers such as carbon-based materials like graphene and carbon nanotube. Wu et al. (2011) prepared a graphene and carbon fiber nanopaper for multifunction composite materials to be used in the aviation such as lightning protection system. Kumar and Sharma (2012) used graphene as replacement materials in fiberreinforced composites to protect against lightning strikes. Vishnyakov et al. (2014) used a conductive nanostructured carbon modifier to improve the electric conductivity of carbon fiber-reinforced plastic laminates to withstand the high currents coming from lightning strikes. Kruckenberg et al. (2015) invented electrically conductive composite reinforced by different nanofiller, such as carbon nanotubes and graphene nanoplates, to protect the aircraft from lightning strikes. Imran (2016) prepared a conductive composite of carbon/epoxy composites by graphene, and he found out that the electrical conductivity is enhanced. Zhang et al. (2017a) fabricated a thin flexible coating made of pristine graphene and applied it on the surface of a commercial carbon fiber epoxy prepreg laminate to protect it against the lightning strike. Kumar et al. (2019) prepared the fabrication of highly conductive graphene thin film (GTF) papers to reduce the possible damage of lightning strikes on composite structures. The GTF is incorporated into carbon fiber reinforced composite panels, and the results have shown that the highest electrical conductivity value measured on GTF papers is approximately $\left(0.18^{\star} 10^{6}\right) \mathrm{S} / \mathrm{m}$, which is close from the electrical conductivity of copper or aluminum. Li et al. (2018) prepared a spray coating of carbon nanoparticles used as a simple technique to increase the electrical and thermal surface conductivity of CFRPs. The use of carbon nanotubes (CNTs) and graphene nanoplatelets (GNPs) synergistically reduced the CFRPs surface resistivity by four orders of magnitude (from $2-3 \Omega /$ sq to $3 \times 10^{-4} \Omega / s q$ ), which will open up the possibilities for the replacement of metallic mesh structures for EMI shielding and LSP.

Epoxy resin is insulated to the electricity, where its electrical conductivity is $10^{-14} \mathrm{~S} / \mathrm{m}$; therefore, epoxy resin can be modified by mixing it with graphene to enhance its electrical conductivity. This modified epoxy resin is later impregnated to the carbon fiber fabric to form new modified carbon fiber epoxy composite that have higher electrical conductivity to withstand the high electrical currents coming from lightning strike. As a result, the weight of the aircraft will be reduced, because these conductive composites will replace the expensive metallic meshes. Table 2 shows a review of some researches done for modifying epoxy resin by different mass fraction ( $\mathrm{w} \%$ ) of different forms for graphene to improve its electrical conductivity. The maximum improvement in electrical conductivity was observed in the case of dip coating and mold casting fabrication methods, which is used by Embrey et al. (2017) disperse $1.91 \mathrm{wt} \%$ of graphene foam in the epoxy, where the electrical conductivity is reached to $500 \mathrm{~S} / \mathrm{m}$. There are another dispersion methods such as ball milling and mechanical stirring used to obtain high values of electrical conductivity. Therefore, both thermal and electrical conductivities improved in the case of mechanical stirring. Epoxy resin without any conductive filler is essentially insulative with an electrical conductivity of (10-14 S/cm), while the GNPs was reported to have excellent electrical conductivity $\left(10^{6} \mathrm{~S} / \mathrm{cm}\right)$. Research studies found that electrical and thermal properties of graphene/epoxy composite depend on the graphene content dispersed in the epoxy matrix. 
Table 2. The variation in electrical conductivity with various forms of graphene and graphite reinforced epoxy composites.

\begin{tabular}{|c|c|c|c|c|}
\hline Sr. & $\begin{array}{l}\text { Reinforcement } \\
\text { [wt \%] }\end{array}$ & Dispersion method & $\begin{array}{l}\text { Enhanced electrical } \\
\text { conductivity }[\mathrm{S} / \mathrm{m}]\end{array}$ & Ref. \\
\hline 1 & GrF (1.91 wt \%) & $\begin{array}{l}\text { Dip coating and mold } \\
\text { casting fabrication } \\
\text { methods }\end{array}$ & 500 & Embrey et al. (2017) \\
\hline 2 & GNPs (4 wt \%) & Three-roll milling & $1.5 \times 10^{-3}$ & $\begin{array}{l}\text { Imran and Shivakumar } \\
\qquad(2018)\end{array}$ \\
\hline 3 & GNPs (5 wt \%) & Mechanical stirring & 100 & Raji et al. (2016) \\
\hline \multirow{2}{*}{4} & EGr $(0.1 \mathrm{wt} \%)$ & \multirow{2}{*}{$\begin{array}{l}\text { Shear mixing and } \\
\text { sonication }\end{array}$} & $1 \times 10^{-5}$ & \multirow{2}{*}{ Chen et al. (2017) } \\
\hline & GNPs $0.1 \mathrm{wt} \%$ & & $5 \times 10^{-3}$ & \\
\hline \multirow{2}{*}{5} & CNTs (0.1 wt \%) & \multirow{2}{*}{$\begin{array}{l}\text { Direct mixing and } \\
\text { sonication }\end{array}$} & $4 \times 10^{-1}$ & \multirow{2}{*}{ Prolongo et al. (2016) } \\
\hline & GNPs (5 wt \%) & & $7 \times 10^{-1}$ & \\
\hline 6 & GNPs (3 wt \%) & $\begin{array}{l}\text { Three roll milling and } \\
\text { sonication }\end{array}$ & $8 \times 10^{-3}$ & Wu et al. (2015) \\
\hline \multirow{2}{*}{7} & GNPs (1.1 wt \%) & \multirow{2}{*}{ Sonication } & $6 \times 10^{-3}$ & \multirow{2}{*}{ Ghaleb et al. (2014) } \\
\hline & MWCNTs (1.9 wt \%) & & $7 \times 10^{-4}$ & \\
\hline 8 & Ag-G (25 wt \%) & $\begin{array}{l}\text { Sonication and mechanical } \\
\text { stirring }\end{array}$ & $4.6 \times 10^{1}$ & Dou et al. (2014) \\
\hline \multirow{2}{*}{9} & GNPs (3 wt \%) & \multirow{2}{*}{$\begin{array}{l}\text { Sonication and mechanical } \\
\text { stirring }\end{array}$} & $5 \times 10^{-4}$ & \multirow{2}{*}{ Monti et al. (2013) } \\
\hline & GNPs (0.24 wt \%) & & $1.2 \times 10^{-9}$ & \\
\hline 10 & FGNs (40 wt \%) & Centrifugal mixing & $8 \times 10^{-2}$ & Al-Ghamdi et al. (2013) \\
\hline 11 & Gr (14 wt \%) & Sonication & $8 \times 10^{-1}$ & Tien et al. (2011) \\
\hline \multirow{2}{*}{12} & GNPs (4.5 wt \%) / CB (0.5 wt \%) & \multirow{2}{*}{$\begin{array}{l}\text { Sonication and mechanical } \\
\text { stirring }\end{array}$} & $6 \times 10^{-4}$ & \multirow{2}{*}{ Fan et al. (2009) } \\
\hline & EGr $(8$ wt \%) & & $1 \times 10^{-6}$ & \\
\hline 13 & FGNPs $(15 \mathrm{w} \%)$ & Sonication & 0.1 & Liang et al. (2009) \\
\hline 14 & MWCNTs (20 wt \%) & Sonication & $5 \times 10^{-3}$ & Li et al. (2007) \\
\hline
\end{tabular}

$\mathrm{GrF}$ = Graphene Foam; GNP = graphene nanoplates; MWCNT = multi wall carbon nanotube; Ag-G = Silver plated graphene; FGNs = Foliated graphite nanosheets; $\mathrm{Gr}=$ Graphite; $\mathrm{CB}$ = carbon black; $\mathrm{EGr}$ = Expanded graphite; FGNPs = Functionalized graphene nanoplates; HSM = Sonicated human serum microspheres

\section{CONDUCTIVE COMPOSITE MATERIALS FOR ELECTROTHERMAL DEICING OF AIRCRAFT SURFACES}

Ice accumulation (see Fig. 11) on the surfaces of an aircraft's leading edge such as wings and tails or within the aircraft's engine is a prevalent problem that degrades the performance of the aircraft. The initial ice accumulation on the leading edge of an aircraft, particularly at temperatures just below freezing, looks like distributed roughness. Roughness affects the aerodynamic performance by altering airflow over the wing and tail, reducing the lift force that keeps the plane in the air, and potentially causing aerodynamic stall - a condition that can lead to a temporary loss of control (minimize lift), causing a significant reduction in aerodynamic ability, i.e. decreasing lift and maneuverability, and increasing drag, weight, and consequently power consumption, as shown in Fig. 12 (Cao et al. 2015; Stothers 2013).

One of the most critical requirements of aerodynamic lift in aircraft flight is a smooth wing surface, and one of the easiest ways to make a wing surface irregular is to add ice to it - a layer of ice even $1 \mathrm{~mm} / 0.04$ inch thick can be enough to destabilize an in-flight airplane. The problem of ice accumulation on aircraft surfaces occurs in certain weather conditions, in particular thunderstorms at high altitudes, which causes small ice crystals to thaw and refreeze until they reach a size large enough to cause problems when they dislodge and get sucked into the engine, leading the engines to lose power for a few seconds after huge ice chunks fly into the core of the engine. Also in instrument meteorological conditions, the pilot's situational awareness is quite poor 
due to the nonexistence of outside visual altitude, navigation, and weather (including icing conditions) and terrain information. The traditional approach to coping with ice accretion problem cannot be farther used efficiently, mainly due to the fact that ice is still a reason for fatal crashes. There is an infinite variety of shapes, thickness, and textures of ice that can accrete at various locations on the airfoil (see Fig. 13). Each ice shape essentially produces a new airfoil with unique lift, drag, stall angle, and pitching moment characteristics that is different from the host airfoil, and from other ice shapes. Therefore, ice protection systems are very important for ensuring the safe operation of an aircraft (Xie et al. 2016; Cao et al. 2015; Stothers 2013; Kind 1998).

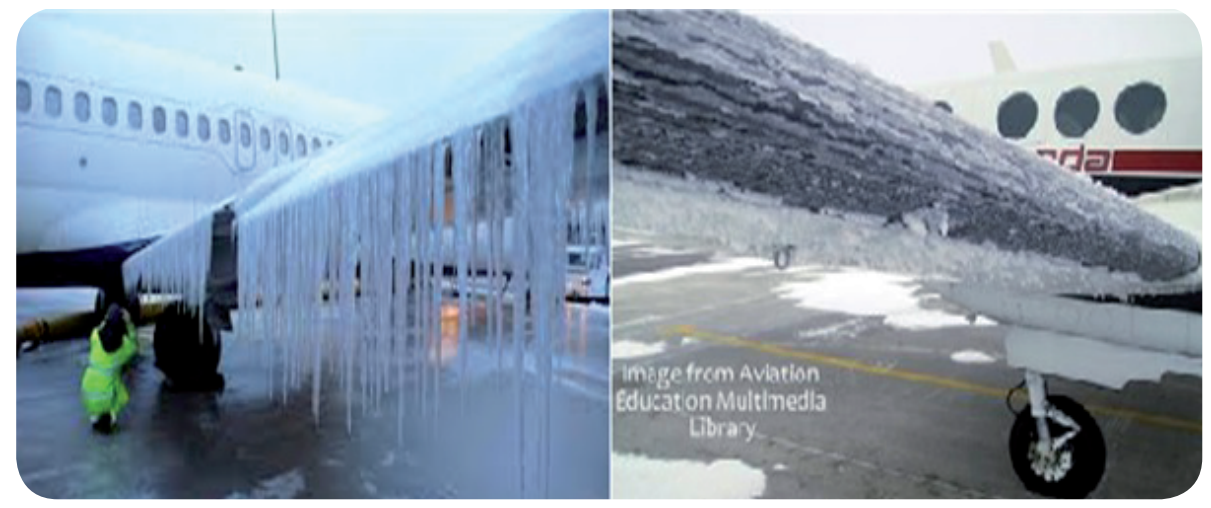

Figure 11. Ice accumulation on aircraft surfaces (Cao et al. 2015; Stothers 2013).

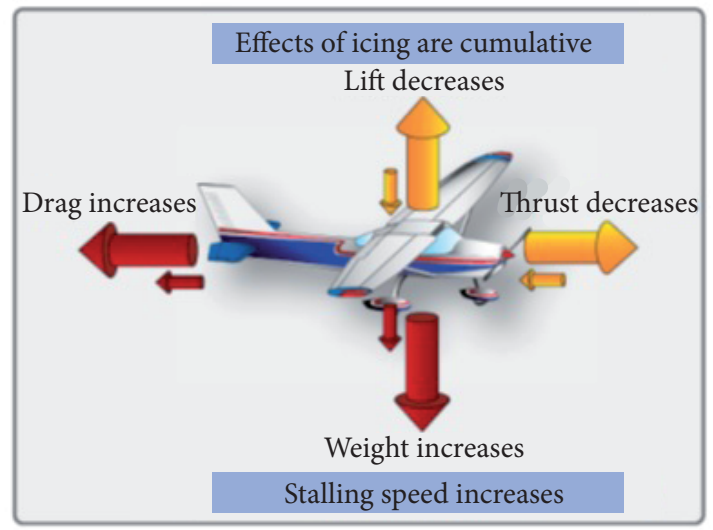

Figure 12. Effects of icing accumulation on aircraft surfaces (Stothers 2013; Kind et al. 1998).

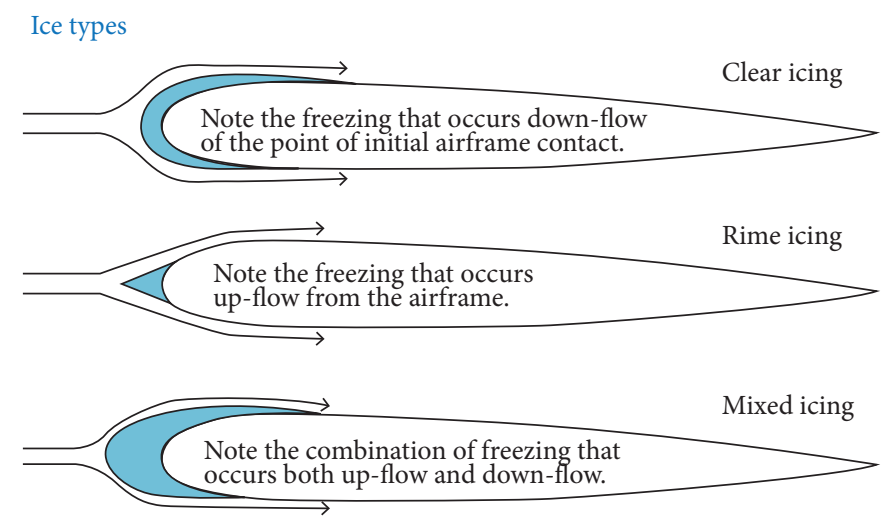

Figure 13. The ice shapes that accumulated on aircraft surfaces (Stothers 2013; Kind et al. 1998). 
Commercial aircrafts are equipped with advanced ice protection systems to deice their surfaces, as shown in Fig. 14. These ice protection systems are classified as deicing systems and anti-icing systems. But most of the current technologies used in aircraft focuses on deicing systems. Different deicing methods have been developed in the aircraft studies. For large commercial aircrafts, the deicing method used is a bleed air method that can remove accumulated ice effectively. Bleed hot air method, which uses the hot air coming from the aircraft jet engine and circulated in the wings of the airplane, or passing through the pipes to the surfaces that need to melt the ice. The air bleed system has two major advantages, firstly, the air is under high pressure, which ensures it will circulate and reach all locations on the aircraft. Secondly, the air coming from the jet engine has a very high temperature, which can easily deice the aircraft's surfaces. The disadvantage of air bleed system is that it requires a jet engine; therefore a small aircraft will not be able to use it (Xie et al. 2016; Cao et al. 2015).

(a)

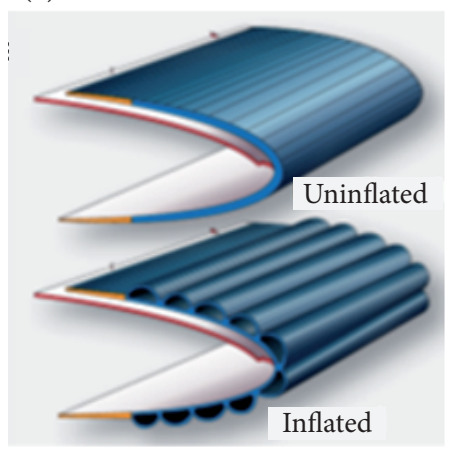

(b)

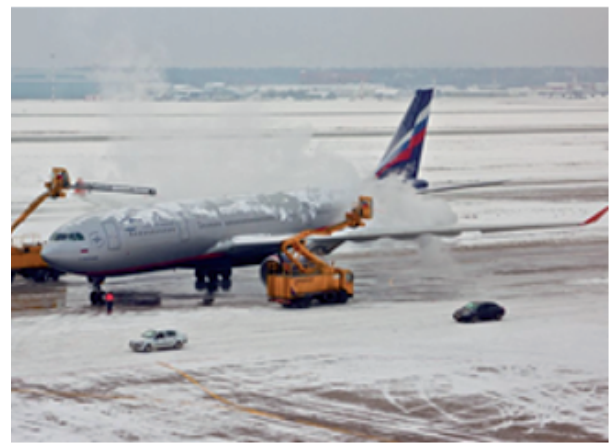

(c)

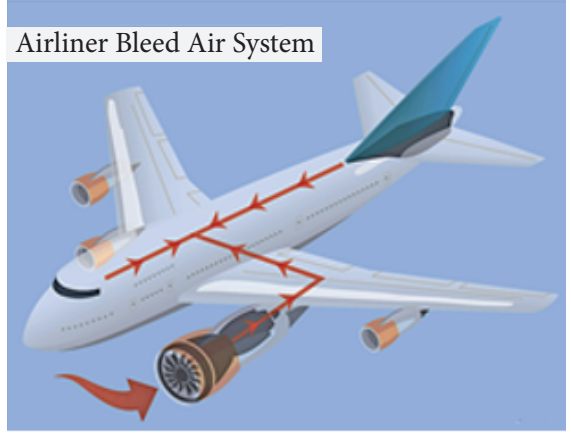

Figure 14. (a) Inflatable rubber boot method, (b) chemical spray method, and (c) bleed air method (Xie et al. 2016; Cao et al. 2015; Stothers 2013).

For small aircrafts, another deicing method is used, the mechanical boot method. This method uses a small device that is put over the leading edge of the wing to remove the accumulated ice. The inflatable rubber boot method uses pneumatic system to inflate the boot and makes it expand to crack the ice accumulated on the surfaces of the aircraft to be removed later by the coming airflow. The boot is then deflated so the wing is returned to its optimal shape. The advantages of this deicing method are that it can efficiently remove ice on a small aircraft, is cheaper and less complex. However, the disadvantages of the mechanical boot system is that is needs ice buildup, because if the accumulated ice is not enough the system will not work, and this can generate dangerous problems for the aircrafts (Xie et al. 2016; Cao et al. 2015; Stothers 2013; Kind et al. 1998). Also the boot system can increase the drag force on the airplane, which can increase the amount of power needed to fly the airplane. In addition to that, the boot system needs frequent costly maintenance. Another anti-icing method used nowadays includes addition of chemical spray to the aircrafts surfaces on the ground during icy condition to prevent building ice on the surfaces. This chemical spray can stay for a long time on the aircraft surfaces. The disadvantage of this anti-icing method that it doesn't work after the aircrafts took off, because the airflow will remove the sprayed fluid leaving the aircraft surfaces clean, and the liquids used can cause environmental problems. In conclusion, all these systems are highly complicated, need a lot of onboard power and demand very careful maintenance. It is especially difficult to accommodate all these traditional systems on smaller commercial aircrafts, for example on business jets, where weight of additional equipment and its complexity can be a real obstacle to install these systems onboard (Xie et al. 2016; Cao et al. 2015; Stothers 2013; Kind et al. 1998).

Significant efforts have been exerted to develop a deicing protection system that simplifies the removal of ice or slow down its formation. The deicing protection systems use a conductive composite material as a heating element by coating the surfaces of the aircraft body to prevent the ice layer building up using joule heating effect. Joule or resistive heating is an electro-thermal technique that results from dissipation of electrical power generated in an electrically conductive material upon applied voltage, and it is an effective, energy-efficient and versatile method of ice removal that is also capable of real-time deicing (Kind et al. 1998; Kim 
2015). During joule heating, a thin layer of ice near the interface between the ice and a heated surface can be melted to generate a layer of water beneath the ice, thereby weakening ice adhesion to facilitate removal by gravity, wind, centrifugal force or inflated pneumatic wrap. The design challenge for such a system is to develop a heating coil, foil or element that can provide consistent heat distribution and be robust and stable. Further, an integrated heating system must be easy to replace in case of damage or malfunction (Petrenko et al. 2011; Mao et al. 2006; Hao-Jun and Da-Wei 2010). Typically, electric heating elements have been made of metallic materials and they have been used for plane heater, wire heater, water heater, industrial process, etc. However, using metal-based electric heating devices in aircrafts have several drawbacks such as oxidative corrosion, high manufacturing costs, and emission of the electromagnetic wave (Zhang et al. 2005; Giamati 1997).

One of the widely used conductive composite materials is organic/reinforcing filler composite, such as graphene/epoxy composite. Epoxy resins as organic have high strength, good stiffness, good thermal stability, excellent heat, moisture and chemical resistance; therefore, they are applied in the field of coatings, adhesives, casting, potting, composites, laminates and encapsulation of semiconductor devices (Mallick 2007). Also, the use of graphene as a conductive nanofiller in the preparation of graphene/ epoxy nanocomposites has attracted the interest in the aerospace field. Graphene/epoxy composites with improved electrical conductivity are utilized in the deicing protection systems in the aircrafts; graphene was found to be very successful in conversion of electric energy to thermal energy in a so-called electro-thermal effect (joule heating), which allows the scientists to build new deicing heater layer composite made of graphene nanoribbons films to be used in ice protection systems (Zhang et al. 2005; Giamati 1997). For two decades, significant research has been carried out regarding the addition of carbon-based materials, such as carbon nanotubes (CNTs) and carbon black, into epoxy matrices in order to enhance the electrical, mechanical and thermal properties of the composites. Despite the achieved success of these carbon materials in improving the electrical properties of epoxy resin, they have many drawbacks that have made them difficult to be used in many applications. For example, using carbon nanotube in composites is still expensive because of the low productivity (Mallick 2007; Volat et al. 2005; Chu 2014), carbon black (CB) is relatively cheap in price, compared to CNT, but an effective electrical conductivity of carbon black/polymer composites is achieved at relatively high concentration of carbon black (Gohardani 2011). On the other hand, graphene sheets can be obtained inexpensively by mass production, compared with CNT, and they also can endow sufficiently high electrical conductivity to polymer composites at low concentration, compared with carbon black. Therefore, graphene nanoplatelets (GNPs) have become an interesting candidate as nanofiller for these polymer matrices (Brittingham et al. 2014).

Graphene/epoxy composites have already shown promising results for creating electrically conductive composites. Electrical current induces the joule heating effect, or self-heating, into nano-reinforced polymers; this heating can be used for different applications such as deicing coatings. The scientists developed new deicing low-voltage heaters based on an ultrathin conductive graphene nanoribbons (GNR) film, resulting in a low sheet resistance, higher thermal conductivity, and excellent heat propagation with uniform temperature distribution (Jeong and An 2014; An and Jeong 2013). An and Jeong (2013) prepared a graphene/ epoxy composite film, obtaining excellent electric heating performance such as rapid temperature response, high electric power efficiency, and operational stability at applied voltages. Monetta et al. (2015) prepared graphene/epoxy coating system by adding graphene nanoflakes into a water-based epoxy resin. The result show enhancement in electrical properties of composite and improved corrosion resistance. Raji et al. (2016) fabricated a conductive composite of graphene nanoribbons (GNR) stacks and epoxy. The GNR-filled epoxy composite exhibits a conductivity $>100 \mathrm{~S} / \mathrm{m}$ at 5 wt \% GNR content. Also, the scientists used graphene or carbon nanotube to modify the carbon fiber reinforced epoxy composite to improve and enhance the electrical and thermal conductivities, to open up the possibilities to be used as a heater to deice aircraft surfaces. Table 3 shows a review of some researches for the enhancement of electrical conductivity of modified carbon fiber/epoxy composite using graphene nanoplates (GNPs). As shown from the table, the electrical conductivity is enhanced and increased by $145 \%$, when graphene nanoplates or carbon nanotubes added to CFRPs. But the electrical conductivity of CFRPs is increased by $257 \%$ when the silver nanoparticles are added to CFRPs; however, using silver will add more weight to the composite, and this is not preferable in aviation.

Studies found that the electrical and thermal conductivities of the epoxy resins are directly proportional to the graphene nanofiller content. The self-heating of epoxy composites also depends on the graphene content, being the self-heating more homogeneous for the GNP/epoxy resins due to their higher thermal conductivity. It was also confirmed that the self-heating is 
Table 3. The enhancement of electrical conductivity of modified carbon fiber/epoxy composite (CFRPs) using graphene.

\begin{tabular}{|c|c|c|c|c|c|}
\hline No & Composite & Matrix/fiber & Filler & $\begin{array}{c}\text { Electrical } \\
\text { conductivity }[\mathrm{S} / \mathrm{m}]\end{array}$ & Ref \\
\hline \multirow{2}{*}{1} & CFRP/GNPs & CF/epoxy & GNPs & 0.6 & \multirow{2}{*}{$\begin{array}{l}\text { Li et al. } \\
\text { (2017) }\end{array}$} \\
\hline & CFRP & CF/epoxy & - & 0.03 & \\
\hline \multirow{3}{*}{2} & CFRP & CF/epoxy & - & 0.07 & \multirow{3}{*}{$\begin{array}{l}\text { Kandare et al. } \\
\text { (2015) }\end{array}$} \\
\hline & CFRP/GNPs & CF/epoxy & GNPs & 0.17 & \\
\hline & CFRP/AgnP & CF/epoxy & AgnP & 0.25 & \\
\hline \multirow{2}{*}{3} & CFRP/GNPs & CF/epoxy & GNPs & 7 & \multirow{2}{*}{ Qin et al. (2015) } \\
\hline & CFRP & CF/epoxy & - & 2.5 & \\
\hline \multirow{2}{*}{4} & $\mathrm{CFRP} / \mathrm{CN}$ & CF/epoxy & $\mathrm{CN}$ & $1.3 \times 104$ & \multirow{2}{*}{$\begin{array}{c}\text { Bekyarova et al. } \\
(2007)\end{array}$} \\
\hline & CFRP & CF/epoxy & - & $6 \times 103$ & \\
\hline
\end{tabular}

AgnP = silver nanoparticles

repetitive in several cycles, reaching the same temperature when the same voltage is applied. Researches also reported the effective synergistic effects of graphene nanoplatelets and CNTs on the enhanced electrical conductivity of epoxy composites, which is ascribed to the formation of a more efficient percolating nanoparticle network. In addition to that, the embedding of hybrids of CNTs and graphene nanoplatelets into pristine epoxy resins showed an excellent electric heating performance in temperature response, electric energy efficiency, and heating-cooling cyclic operation at given applied voltages, as well as better interfacial adhesion between the carbon fillers and matrix, which leads to a significant improvement in load transfer effectiveness. The conductive graphene composite films must be extremely tough with good adhesiveness to the heated surface, such film must be light-weight and low cost, with physical characteristics that allow it to cover large curved surface areas (Huang et al. 2012; Safdari and Al-Haik 2013; Kuilla et al. 2010).

There are many Patents on using conductive graphene composites as a deicing element heater in the aircrafts, scientists invented a graphene/epoxy electrothermal film that would solve the icing problem without introducing the common drawbacks; it is safe in working voltage, high in thermal conversion efficiency, fine in thermal conductivity, quick in response, and fine in tenacity. For example, Li et al. (2014) and Burton et al. (2016) described configurations to provide uniform heat distribution of resistive heaters. This configuration allows successful anti-icing and deicing with relatively low applied power. Also Karim et al. (2018) and Lui and Hui (2016) mixed Graphene nanoplatelets with a polymer resin. The resin is then painted onto the aircraft surfaces, providing a tight jacket around all airplane components. When ice catches on a part of the airplane, that part (or the entire plane exterior) can be heated by running an electric current through the conductive jacket. The proposed concept of combining superrepellency with electrothermal heating may provide a new strategy for addressing problems related to ice formation. Tour $e t$ al. (2016) and Matsubayashi et al. (2016) invented the conductive superhydrophobic coatings for preventing or reducing ice formation on a surface of aircraft by repulsion of water from the surface. Excellent water repellency and efficient heating ability generated by applying the voltage through the conductive film surface have been demonstrated.

A new smart system is composed of bi-stable composite structures, which have the advantages of lightweight and multifunctional characteristics. The actuation of a bi-stable skin can be for deicing system, where a change in the shape can detach an ice layer on the aircraft's surface. Bi-stable composite structures have two different kinds of stable configurations ('State-I' and 'State-II'), as shown in Fig. 15. These structures can be changed from one stable shape to another with external actuation to induce 'snapthrough' between states or a change of shape in a single state, such as temperature fields, mechanical forces, piezoelectric materials and electromagnetism. Such laminate structures are finding interest applications such as shape-changing, energy harvesting and deicing. Bi-stable composite structures are usually manufactured from carbon fiber or glass fiber/resin matrix composites; therefore, the mechanical properties of bi-stable composite structures are sensitive to the variations of the ambient temperature, moisture and the loading time. When the bi-stable structures are subjected to a temperature gradient field, then it is possible to snap to another stable configuration (Zhang et al. 2014; 2018c). Zhang et al. (2017b) investigated anti-icing and deicing protection systems 
that include bi-stable composite structures with superhydrophobic surface and electrothermal patch, as shown in Fig. 16. The superhydrophobic surface reduces the adhesion of the ice to the aircraft skin. The electrothermal patch provides actuating force for a bi-stable composite to change its shape and transfer the thermal energy. The results show that the system performances are efficient in anti-icing and deicing systems when working at very low temperature. The ice on the surface of structures is melted completely by heating the bi-stable structures. It is found that no water is left on the aircraft's surface after the snap-through process of the bi-stable structure.

On the other hand, scientists prepared functionally graded materials (FGMs) that have excellently mechanical properties and environmental resistance. FGMs are designed with changing properties over the volume of the bulk material. FGMs are manufactured with varying properties that include changing of chemical properties, mechanical, magnetic, thermal, and electrical properties. The variation of properties in FGMs can reduce the thermal stresses, residual stresses, and stress concentrations found in the composites. A FGM's gradation in material properties leads the designers to tailor material response to satisfy the design needs. By varying the volume fraction of the carbon fiber in the carbon fiber epoxy composite, functionally graded material laminated shell is obtained, which can be utilized in the aircraft applications such as deicing process, where the required electrical and thermal conductivities needed for efficient deicing can be obtained. The material properties of this kind of FGM shell continuously change with the material components along the thickness direction. Recently, researchers used aligned carbon nanotube web to build a deicing system for aircrafts surfaces (Zhang et al. 2018a; Liew et al. 2015). Carbon nanotube (CNT) web is a horizontally oriented continuous film obtained by drawing CNT forests with controlled diameter and length, produced by chemical vapour deposition (CVD). CNT webs have high electrical conductivity in the drawing direction, hence, the electrical resistance of CNT

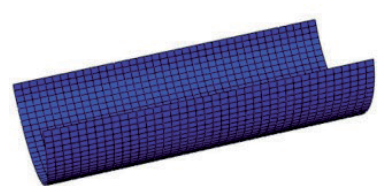

Initial stable state

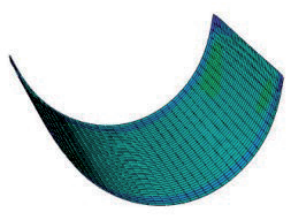

Second stable state

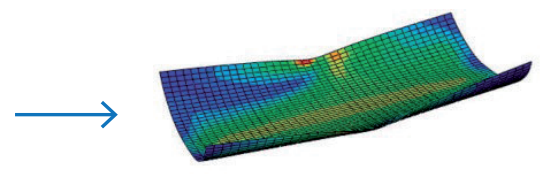

Snapping proces

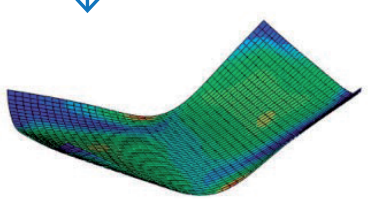

Figure 15. Two different kinds of stable configurations for bi-stable laminate structures (Zhang et al. 2018b).

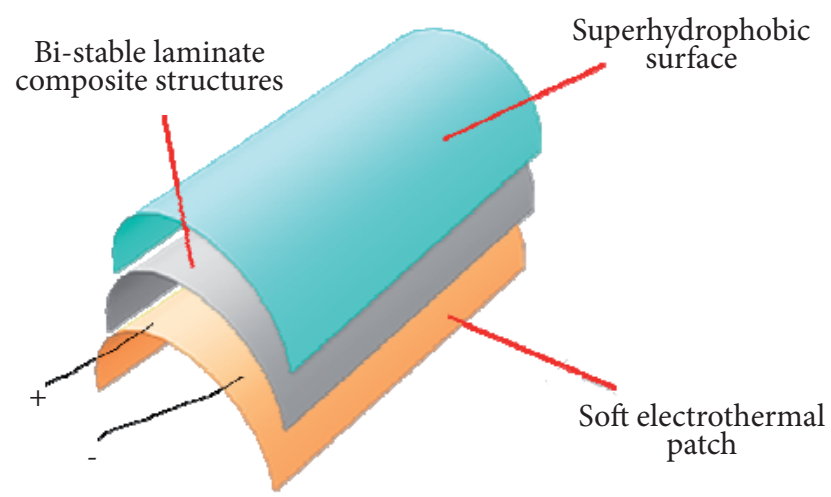

Figure 16. Schematic diagram of the anti-icing/deicing system (Zhang et al. 2017b). 
web laminate can be easily changed by varying the number of layers. Therefore, CNT web was utilized as an electro-thermal heating element for anti-icing and deicing of composite structures. Highly aligned CNT-web-heater has negligible weight, quick and uniform heating, economical energy consumption, is compatible with CFR, and can be tuned both in terms of shape and performance to suit any surface and power requirement to achieve rapid deicing (Yao et al. 2018, Molnár et al. 2014). Yao et al. (2018) investigated improved anti-icing and deicing systems made of highly aligned carbon nanotube webs. The results show that the carbon fiber laminate with layers of CNT web reached both anti-icing and deicing successfully. Each anti-icing/deicing performance is verified. For deicing, with a constant power supply, the laminate that has 40 layers of CNT webs can remove the accumulated ice within 15 seconds.

\section{FUTURE TRENDS OF CONDUCTIVE COMPOSITE TECHNOLOGY IN AVIATION}

The goal for the future conductive composite materials is to present a mix of innovative near-term practical applications for aviation, as well as ideas to inspire novel solutions to present and future challenges in aircrafts design. Conductive composite materials will, within ten years, replace the metal meshes (such as copper mesh) currently used in lightning protection systems in aircrafts because they can reduce the aircraft weight and carry the lightning currents effectively. Furthermore, conductive composite materials can be investigated as a method to provide electrothermal anti-icing/deicing composite to the new generation of aircrafts, and it can replace metal-based electric heating devices which have several drawbacks such as oxidative corrosion, high manufacturing costs, heavyweight and emission of an electromagnetic wave. Improving the aircraft performance and reducing the airframe weight can be achieved with new conductive composite materials because such materials combine very useful mechanical, thermal, electrical and physical properties. Carbon nanotubes and/or graphene may eventually replace carbon fibers in composites for future aircraft and other challenging applications; therefore future airframes will include multifunctional structure (Zhao et al. 2011, Ely and Ketcham 1950).

The addition of graphene to change one of the fundamental characteristics of the base resin could lead to a whole new generation of graphene enhanced composite materials. The performance of the carbon fiber heater matched that of a similar laminate made with a metallic heating filament for icing protection applications. Also, the performance of the carbon fiber heater can be improved by adding graphene to the composite, since it has excellent thermal and electrical properties that can enhance the thermal and electrical conductivities of carbon fiber reinforced epoxy composite (Barbier et al. 1988).

\section{CONCLUSION}

Conductive composites include any composite having significant electrical or thermal conductivity, being the electrical conductivity of a composite generally characterized by its dependence on filler volume fraction, as the filler amount in the composite is increased, the fillers particles begin to contact each other, and a continuous path is formed through the volume of the sample for electrons to travel. Conductive composite materials have been used also to improve thermal management systems for transferring heat in the aerospace vehicles. The required enhancements include increased thermal conductivity, increased surface area, reduced weight/volume, as well as operability in harsh environments, such as durability under high flow rates, vibrations, stress, elevated temperatures, and oxidative environments.

Conductive polymer composites offer more reliable electrical conductivity and better mechanical properties than intrinsic conductive polymeric materials. This is significant, especially because good mechanical properties are important to replace the metallic parts. Polymer conductive composites are functional composites made by adding conductive fillers to polymers using a specified processing method, yielding steady and sustained electrical conductivity. Conductive composite materials are used to develop surfaces used in aircraft skins to solve some problems in the aviation such as lightning strike and icing that can affect the performance and operation of the aircraft. For two decades, significant research has been carried out regarding the addition of 
carbon nanotubes (CNTs) into epoxy matrices in order to enhance the electrical, mechanical and thermal properties. Recently, graphene nanoplatelets (GNPs) have become an interesting candidate as nanofiller for these polymer matrices.

\section{AUTHOR'S CONTRIBUTION}

Conceptualization, Alemour B, Hassan MR; Methodology, Alemour B, Bradan O, Hassan MR; Investigation, Alemour B, Bradan O, Hassan MR; Writing - Original Draft, Alemour B; Writing - Review and Editing, Alemour B, Bradan O, Hassan MR; Supervision, Alemour B.

\section{REFERENCES}

Advani SG, Tucker III CL (1987) The use of tensors to describe and predict fiber orientation in short fiber composites. Journal of Rheology 31(8):751-784. https://doi.org/10.1122/1.549945

Al-Ghamdi AA, Al-Hartomy OA, Al-Solamy F, Al-Ghamdi Attieth A, El-Tantawy F (2013) Electromagnetic wave shielding and microwave absorbing properties of hybrid epoxy resin/foliated graphite nanocomposites. Journal of Applied Polymer Science 127(3):2227-2234. https://doi. org/10.1002/app.37904

Al-Saleh MH, Sundararaj U (2009) A review of vapor grown carbon nanofiber/polymer conductive composites. Carbon 47(1):2-22. https://doi. org/10.1016/i.carbon.2008.09.039

An JE, Jeong YG (2013) Structure and electric heating performance of graphene/epoxy composite films. European Polymer Journal 49(6):13221330. https://doi.org/10.1016/i.eurpolymi.2013.02.005

Andersson F, Hagqvist A, Sundin E, Björkman M (2014) Design for manufacturing of composite structures for commercial aircraft - the development of a DFM strategy at SAAB aerostructures. Procedia CIRP 17:362-367.https://doi.org/10.1016/j.procir.2014.02.053

Ashby MF, Johnson K (2013) Materials and design: the art and science of material selection in product design. Oxford: Butterworth-Heinemann

Ashrafi B, Guan J, Mirjalili V, Hubert P, Simard B, Johnston A (2010) Correlation between Young's modulus and impregnation quality of epoxyimpregnated SWCNT buckypaper. Composites Part A: Applied Science and Manufacturing 41(9):1184-1191. https://doi.org/10.1016/j. compositesa.2010.04.018

Bakis CE, Bank LC, Brown V, Cosenza E, Davalos JF, Lesko JJ, Machida A, Rizkalla SH, Triantafillou TC (2002) Fiber-reinforced polymer composites for construction-State-of-the-art review. Journal of composites for construction 6(2):73-87. https://doi.org/10.1061/(ASCE)10900268(2002)6:2(73)

Barbier P, Cohendy A, Reynet R (1988) Heating element for a defrosting device for a wing structure, such a device and a process for obtaining same. US Patent No. 4737618A.

Baur J, Silverman E (2007) Challenges and opportunities in multifunctional nanocomposite structures for aerospace applications. MRS bulletin 32(4):328-334. https://doi.org/10.1557/mrs2007.231

Bekyarova E, Thostenson ET, Yu A, Kim H, Gao J, Tang J, Hahn HT, Chou T-W, Itkis ME, Haddon RC (2007) Multiscale carbon nanotube- carbon fiber reinforcement for advanced epoxy composites. Langmuir 23(7):3970-3974. https://doi.org/10.1021/la062743p

Brick RO (1988) Lightning protection system for conductive composite material structure. US Patent No. 4755904A.

Brittingham DL, Prybyla SG, Christy DP (2014) Methods of protecting an aircraft component from ice formation. US Patent No. 875227982.

Burton B, Heintz AM, Bosworth K, Duong T, Jansen M (2016) Uniform heat distribution in resistive heaters for anti-icing and de-icing. US Patent Application No. 14/988742.

Chamis CC (1989) Mechanics of composite materials: past, present, and future. Journal of Composites, Technology and Research 11(1):3-14. https://doi.org/10.1520/CTR10143J

Campbell FC (2010) Structural composite materials. Materials Park: ASM international.

Cao Y, Wu Z, Su Y, Xu Z (2015) Aircraft flight characteristics in icing conditions. Progress in Aerospace Sciences 74:62-80. https://doi. org/10.1016/i.paerosci.2014.12.001

Chemartin L, Lalande P, Peyrou B, Chazottes A, Elias PQ, Delalondre C, Cheron BG, Lago F (2012) Direct effects of lightning on aircraft structure: 
analysis of the thermal, electrical and mechanical constraints. J AerospaceLab 5:1-15.

Chen L, Zhang Y, Wu Q (2017) Effect of graphene coating on the heat transfer performance of a composite anti-/deicing component. Coatings 7(10):158. https://doi.org/10.3390/coatings7100158

Cho YS, Huh YD (2009) Synthesis of ultralong copper nanowires by reduction of copper-amine complexes. Materials Letters 63(2):227-229. https://doi.org/10.1016/i.matlet.2008.09.049

Chu H, Zhang Z, Liu Y, Leng J (2014) Self-heating fiber reinforced polymer composite using meso/macropore carbon nanotube paper and its application in deicing. Carbon 66:154-163. https://doi.org/10.1016/i.carbon.2013.08.053

Chung DD (2010) Composite materials: science and applications. London: Springer.

Clough RL, Sylwester AP (1989) Electrically conductive composite material. US Patent No. 4832870A.

Dou S, Qi J, Guo X, Yu C (2014) Preparation and adhesive performance of electrical conductive epoxy-acrylate resin containing silver-plated graphene. Journal of Adhesion Science and Technology 28(16):1556-1567. https://doi.org/10.1080/01694243.2014.904766

Du S (2007) Advanced composite materials and aerospace engineering. Fuhe Cailiao Xuebao (Acta Mater. Compos. Sin.) 24(1):1-12.

Dutton S, Kelly D, Baker A (2004) Composite materials for aircraft structures. Reston: AlAA. https://doi.org/10.2514/4.861680

Ely RS, Ketcham IM (1950) Flexible electric heater for deicing airfoils. US Patent No. 2496279A.

Embrey L (2017) Three-Dimensional Graphene Foam Reinforced Epoxy Composites (Master's Thesis). Miami: Florida International University. https://doi.org/10.25148/etd.FIDCO01819

Fan J, Njuguna J (2016) An introduction to lightweight composite materials and their use in transport structures. In: Njuguna J, editor. Lightweight Composite Structures in Transport (p. 3-34). Sawston: Woodhead Publishing. https://doi.org/10.1016/B978-1-78242-325-6.00001-3

Fan Z, Zheng C, Wei T, Zhang Y, Luo G (2009) Effect of carbon black on electrical property of graphite nanoplatelets/epoxy resin composites. Polymer Engineering \& Science 49(10):2041-2045. https://doi.org/10.1002/pen.21445

Fiske TJ, Gokturk HS, Kalyon DM (1997) Percolation in magnetic composites. Journal of materials science 32(20):5551-5560. https://doi. org/10.1023/A:1018620407013

Gagné M, Therriault D (2014) Lightning strike protection of composites. Progress in Aerospace Sciences 64:1-16. https://doi.org/10.1016/i. paerosci.2013.07.002

Gammon LM, Falcone A (2003) Lightning strike damage in polymer composites. Advanced materials \& processes 161(8):61-62.

Gardner G (2006) Lightning strike protection for composite structures. High performance composites 14(4):44.

Gay D, Hoa SV (2007) Composite materials: design and applications. 2nd ed. Boca Raton: CRC press. https://doi.org/10.1201/9781420045208

Ghaleb ZA, Mariatti M, Ariff ZM (2014) Properties of graphene nanopowder and multi-walled carbon nanotube-filled epoxy thin-film nanocomposites for electronic applications: the effect of sonication time and filler loading. Composites Part A: Applied Science and Manufacturing 58:77-83. https://doi.org/10.1016/i.compositesa.2013.12.002

Giamati MJ (1997) Electrothermal de-icing system. US Patent No. 5657951A.

Gibson RF (2010) A review of recent research on mechanics of multifunctional composite materials and structures. Composite structures 92(12):2793-2810. https://doi.org/10.1016/i.compstruct.2010.05.003

Gohardani $\mathrm{O}$ (2011) Impact of erosion testing aspects on current and future flight conditions. Progress in Aerospace Sciences 47(4):280-303. https://doi.org/10.1016/i.paerosci.2011.04.001

Göktürk HS, Fiske TJ, Kalyon DM (1993) Effects of particle shape and size distributions on the electrical and magnetic properties of nickel/ polyethylene composites. Journal of applied polymer science 50(11):1891-1901. https://doi.org/10.1002/app.1993.070501105

Goraj Z (2004) An overview of the deicing and anti-icing technologies with prospects for the future. Presented at: 24th International Congress of the Aeronautical Sciences; Yokohama, Japan.

Gou J, Tang Y, Liang F, Zhao Z, Firsich D, Fielding J (2010) Carbon nanofiber paper for lightning strike protection of composite materials. Composites Part B: Engineering 41(2):192-198. https://doi.org/10.1016/i.compositesb.2009.06.009

Hale J (2006) Boeing 787 from the ground up. Aero 4(24):7.

Hao-Jun ZLX, Da-Wei GSKL (2010) Research of aircraft icing characteristics and anti-icing and de-icing technology. China Safety Science Journal 6:21.

Hartman P, Narducci R, Peterson A, Dadone L, Mingione G, Zanazzi G, Brandi V (2006) Prediction of ice accumulation and airfoil performance degradation: a Boeing-CIRA research collaboration. Presented at: 62nd Annual Forum for the American Helicopter Society; Phoenix, USA.

Hsieh TH, Chen WJ, Chiang CL, Shen MY (2018) Environmental aging effect on interlaminar properties of graphene nanoplatelets 
reinforced epoxy/carbon fiber composite laminates. Journal of Reinforced Plastics and Composites 37(19):1177-1190. https://doi. org/10.1177/0731684416637219

Huang X, Zhi C, Jiang P (2012) Toward effective synergetic effects from graphene nanoplatelets and carbon nanotubes on thermal conductivity of ultrahigh volume fraction nanocarbon epoxy composites. The Journal of Physical Chemistry C 116(44):23812-23820. https://doi.org/10.1021/ jp308556r

Imran K (2016) Enhancement of electrical conductivity of carbon/epoxy composites by graphene and assessment of thermal and mechanical properties (PhD Dissertation). Greensboro: North Carolina Agricultural and Technical State University.

Imran KA, Shivakumar KN (2018) Enhancement of electrical conductivity of epoxy using graphene and determination of their thermo-mechanical properties. Journal of Reinforced Plastics and Composites 37(2):118-133.https://doi.org/10.1177/0731684417736143

Jeong YG, An JE (2014) Effects of mixed carbon filler composition on electric heating behavior of thermally-cured epoxy-based composite films. Composites Part A: Applied Science and Manufacturing 56:1-7.https://doi.org/10.1016/j.compositesa.2013.09.003

Kalaitzidou K, Fukushima H, Drzal LT (2007) A new compounding method for exfoliated graphite-polypropylene nanocomposites with enhanced flexural properties and lower percolation threshold. Composites Science and Technology 67(10):2045-2051.https://doi.org/10.1016/i. compscitech.2006.11.014

Kandare E, Khatibi AA, Yoo S, Wang R, Ma J, Olivier P, Gleizes N, Wang CH (2015) Improving the through-thickness thermal and electrical conductivity of carbon fibre/epoxy laminates by exploiting synergy between graphene and silver nano-inclusions. Composites Part A: Applied Science and Manufacturing 69:72-82. https://doi.org/10.1016/j.compositesa.2014.10.024

Karim N, Zhang M, Afroj S, Koncherry V, Potluri P, Novoselov KS (2018) Graphene-based surface heater for de-icing applications. RSC Advances 8:16815-16823.https://doi.org/10.1039/C8RA02567C

Katunin A, Krukiewicz K, Turczyn R, Sul P, Bilewicz M (2017) Electrically conductive carbon fibre-reinforced composite for aircraft lightning strike protection. Presented at: 7th International Conference on Key Engineering Materials; Penang, Malaysia. https://doi.org/10.1088/1757899x/201/1/012008

Kaur G, Adhikari R, Cass P, Bown M, Gunatillake P (2015) Electrically conductive polymers and composites for biomedical applications. RSC Advances 5:37553-37567.https://doi.org/10.1039/C5RA01851J

Kim JW (2015) Development of a physics based methodology for the prediction of rotor blade ice formation (PhD Dissertation). Atlanta: Georgia Institute of Technology.

Kind RJ, Potapczuk MG, Feo A, Golia C, Shah AD (1998) Experimental and computational simulation of in-flight icing phenomena. Progress in Aerospace Sciences 34(5-6):257-345.https://doi.org/10.1016/S0376-0421(98)80001-8

Kirby MR, Mavris DN (2001) A technique for selecting emerging technologies for a fleet of commercial aircraft to maximize R\&D investment. SAE Transactions Journal of Aerospace 110(1):3018. https://doi.org/10.4271/2001-01-3018

Kruckenberg TM, Hill VA, Mazany AM, Young E, Chiou S (2015) Low density lightning strike protection for use in airplanes. US Patent No. $8962130 \mathrm{~B} 2$

$\mathrm{Ku} \mathrm{H}$, Wang H, Pattarachaiyakoop N, Trada M (2011) A review on the tensile properties of natural fiber reinforced polymer composites. Composites Part B: Engineering 42(4):856-873. https://doi.org/10.1016/i.compositesb.2011.01.010

Kuilla T, Bhadra S, Yao D, Kim NH, Bose S, Lee JH (2010) Recent advances in graphene based polymer composites. Progress in Polymer Science 35(11):1350-1375. https://doi.org/10.1016/i.progpolymsci.2010.07.005

Kumar A, Sharma S (2012) Incorporation of graphene thin films into the carbon fiber reinforced composite via 3d composite concept against the lightning strikes on composite aircraft (Master's Thesis). Wichita: Wichita State University.

Kumar SS, Uddin MN, Rahman MM, Asmatulu R (2019) Introducing graphene thin films into carbon fiber composite structures for lightning strike protection. Polymer Composites 40(51):E517-525. https://doi.org/10.1002/pc.24850

Li J, Ma PC, Chow WS, To CK, Tang BZ, Kim JK (2007) Correlations between percolation threshold, dispersion state, and aspect ratio of carbon nanotubes. Advanced Functional Materials 17(16):3207-3215. https://doi.org/10.1002/adfm.200700065

Li J, Wang G, Zhu H, Zhang M, Zheng X, Di Z, Liu X, Wang X (2014) Antibacterial activity of large-area monolayer graphene film manipulated by charge transfer. Scientific Reports 4:4359. https://doi.org/10.1038/srep04359

Li Y, Zhang H, Liu Y, Wang H, Huang Z, Peijs T, Bilotti E (2018) Synergistic effects of spray-coated hybrid carbon nanoparticles for enhanced electrical and thermal surface conductivity of CFRP laminates. Composites Part A: Applied Science and Manufacturing 105:9-18. https://doi. org/10.1016/j.compositesa.2017.10.032

Li Y, Zhang H, Huang Z, Bilotti E, Peijs T (2017) Graphite nanoplatelet modified epoxy resin for carbon fibre reinforced plastics with enhanced properties. Journal of Nanomaterials 2017:5194872. https://doi.org/10.1155/2017/5194872

Liang J, Wang Y, Huang Y, Ma Y, Liu Z, Cai J, Zhang C, Gao H, Chen Y (2009) Electromagnetic interference shielding of graphene/epoxy composites. Carbon 47(3):922-925. https://doi.org/10.1016/j.carbon.2008.12.038 
Liew KM, Lei ZX, Zhang LW (2015) Mechanical analysis of functionally graded carbon nanotube reinforced composites: a review. Composite Structures 120:90-97. https://doi.org/10.1016/i.compstruct.2014.09.041

Lubin G, editor (2013) Handbook of composites. Boston: Springer. https://doi.org/10.1007/978-1-4615-7139-1

Lui F, Hui C (2016) Electrothermal coating with nanostructures mixture and method for making the same. US Patent Application No. $14 / 789617$.

Mallick PK (2007) Fiber-reinforced composites: materials, manufacturing, and design. Boca Raton: CRC press.

Mamunya EP, Davidenko WV, Lebedev EV (1996) Effect of polymer-filler interface interactions on percolation conductivity of thermoplastics filled with carbon black. Composite Interfaces 4(4):169-176. https://doi.org/10.1163/156855497X00145

Mangalgiri PD (1999) Composite materials for aerospace applications. Bulletin of Materials Science 22(3):657-664. https://doi.org/10.1007/ BFO2749982

Mao X, Ter Mors A, Roos N, Witteveen C (2006) Agent-based scheduling for aircraft deicing. Presented at: 18th BeNeLux Conference on Artificial Intelligence; Namur, Belgium.

Matsubayashi T, Tenjimbayashi M, Manabe K, Komine M, Navarrini W, Shiratori S (2016) Integrated anti-icing property of super-repellency and electrothermogenesis exhibited by PEDOT: PSS/cyanoacrylate composite nanoparticles. ACS Applied Materials \& Interfaces 8(36):24212-24220. https://doi.org/10.1021/acsami.6b07844

McCullough KA (2000) Thermally conductive composite material. US Patent No. 6048919A.

Molnár K, Szebényi G, Szolnoki B, Marosi G, Vas LM, Toldy A (2014) Enhanced conductivity composites for aircraft applications: carbon nanotube inclusion both in epoxy matrix and in carbonized electrospun nanofibers. Polymers for Advanced Technologies 25(9):981-988. https://doi. org/10.1002/pat.3339

Monetta T, Acquesta A, Bellucci F (2015) Graphene/epoxy coating as multifunctional material for aircraft structures. Aerospace 2(3):423-434. https://doi.org/10.3390/aerospace2030423

Monti M, Rallini M, Puglia D, Peponi L, Torre L, Kenny JM (2013) Morphology and electrical properties of graphene-epoxy nanocomposites obtained by different solvent assisted processing methods. Composites Part A: Applied Science and Manufacturing 46:166-172. https://doi. org/10.1016/i.compositesa.2012.11.005

Morgan $J$ (2013) Thermal simulation and testing of expanded metal foils used for lightning protection of composite aircraft structures. SAE International Journal of Aerospace 6(2):371-377. https://doi.org/10.4271/2013-01-2132

Mouritz AP, Gellert E, Burchill P, Challis K (2001) Review of advanced composite structures for naval ships and submarines. Composite structures 53(1):21-42. https://doi.org/10.1016/S0263-8223(00)00175-6

Nagata K, Iwabuki H, Nigo H (1998) Effect of particle size of graphites on electrical conductivity of graphite/polymer composite. Composite interfaces 6(5):483-495. https://doi.org/10.1163/156855499X00161

Nayak NV (2014) Composite materials in aerospace applications. International Journal of Scientific and Research Publications 4(9):1-10.

Peters ST, editor (2013) Handbook of composites. Boston: Springer Science \& Business Media.

Petrenko VF, Sullivan CR, Kozlyuk V, Petrenko FV, Veerasamy V (2011) Pulse electro-thermal de-icer (PETD). Cold Regions Science and Technology 65(1):70-78. https://doi.org/10.1016/j.coldregions.2010.06.002

Prolongo SG, Moriche R, Del Rosario G, Jiménez-Suárez A, Prolongo MG, Ureña A (2016) Joule effect self-heating of epoxy composites reinforced with graphitic nanofillers. Journal of Polymer Research 23(9):189. https://doi.org/10.1007/s10965-016-1092-4

Qin W, Vautard F, Drzal LT, Yu J (2015) Mechanical and electrical properties of carbon fiber composites with incorporation of graphene nanoplatelets at the fiber-matrix interphase. Composites Part B: Engineering 69:335-341. https://doi.org/10.1016/j.compositesb.2014.10.014

Rachidi F, Rubinstein M, Montanya J, Bermudez JL, Sola RR, Sola G, Korovkin N (2008) A review of current issues in lightning protection of newgeneration wind-turbine blades. IEEE Transactions on Industrial Electronics 55(6):2489-2496. https://doi.org/10.1109/TIE.2007.896443

Raji ARO, Varadhachary T, Nan K, Wang T, Lin J, Ji Y, Genorio B, Nhu Y, Kittrell C, Tour JM (2016) Composites of graphene nanoribbon stacks and epoxy for joule heating and deicing of surfaces. ACS Applied Materials \& Interfaces 8(5):3551-3556. https://doi.org/10.1021/ acsami.5b11131

Renton WJ, Olcott D, Roeseler W, Batzer R, Baron W, Velicki A (2004) Future of flight vehicle structures (2000 to 2023). Journal of Aircraft 41(5):986-998. https://doi.org/10.2514/1.4039

Roeseler WG, Sarh B, Kismarton MU (2007) Composite structures: the first 100 years. Presented at: 16th International Conference on Composite Materials; Kyoto, Japan.

Rosato D (2013) Designing with plastics and composites: a handbook. Boston: Springer Science \& Business Media.

Ruschau GR, Yoshikawa S, Newnham RE (1992) Resistivities of conductive composites. Journal of applied physics 72(3):953-959. https://doi. org/10.1063/1.352350 
Safdari M, Al-Haik MS (2013) Synergistic electrical and thermal transport properties of hybrid polymeric nanocomposites based on carbon nanotubes and graphite nanoplatelets. Carbon 64:111-121. https://doi.org/10.1016/i.carbon.2013.07.042

Sardiwal SK, Sami MA, Anoop BS, Susmita G, Arsha LVS (2014) Advanced composite materials in typical aerospace applications. Global Journal of Researchs In Engineering 14(1):4-10.

Soutis C (2005) Carbon fiber reinforced plastics in aircraft construction. Materials Science and Engineering: A 412(1-2):171-176. https://doi. org/10.1016/j.msea.2005.08.064

Stothers IMG (2013) Ice protection system. US Patent No. 8602359B2.

Suzuki Y, Suzuki T, Todoroki A, Mizutani Y (2014) Smart lightning protection skin for real-time load monitoring of composite aircraft structures under multiple impacts. Composites Part A: Applied Science and Manufacturing 67:44-54. https://doi.org/10.1016/i.compositesa.2014.08.010

Sweers G, Birch B, Gokcen J (2012) Lightning Strikes: Protection, inspection, and repair. Aero Magazine 4:19-28.

Tien DH, Park J, Han SA, Ahmad M, Seo Y, Shin K (2011) Electrical and thermal conductivities of stycast 1266 epoxy/graphite composites. J Korean Phy Soc 59(4):2760-2764.

Tour JM, Volman V, Raji A-R, Kovalchuk A, Wang T, Zheng Y (2016) Graphene nanoribbon layers for de-icing and anti-icing applications. US Patent Application No. PCT/US2015/061497.

Tsekmes IA, Kochetov R, Morshuis PHF, Smit JJ (2013) Thermal conductivity of polymeric composites: a review. Presented at: 2013 IEEE International Conference on Solid Dielectrics; Bologna, Italy. https://doi.org/0.1109/ICSD.2013.6619698

Vander Voort GF (2004) Metallography and microstructures. ASM Handbook 9. Materials Park: ASM International.

Vishnyakov LR, Pereselentseva LN, Vishnyakova EL (2014) Knitted Soldered Meshes and Nanostructured Carbon Particles for Lightning Protection of Composite Wind Turbine Blades. Powder Metallurgy and Metal Ceramics 53(5-6):368-374. https://doi.org/10.1007/s11106-014-9625-z

Volat C, Farzaneh M, Leblond A (2005) De-icing/anti-icing techniques for power lines: current methods and future direction. Presented at: 11th International Workshop on Atmospheric lcing of Structures; Montreal, Canada.

Welch JM (2007) Repair design, test, and process considerations for lightning strikes. Presented at: Joint FAA-Boeing-Airbus Damage Tolerance Workshop; Amsterdam, The Netherlands.

Werfelman L (2007) The Composite Evolution. AeroSafety World 2(3):17-21.

White MA (2011) Physical properties of materials. Boca Raton: CRC press.

Wu C, Lu H, Liu L, Liu Y, Leng J (2011) Graphene and carbon nanofiber nanopaper for multifunction composite materials. Presented at: SPIE Smart Structures and Materials; San Diego, USA. https://doi.org/10.1117/12.880364

Wu S, Ladani RB, Zhang J, Bafekrpour E, Ghorbani K, Mouritz AP, Kinloch AJ, Wang CH (2015) Aligning multilayer graphene flakes with an external electric field to improve multifunctional properties of epoxy nanocomposites. Carbon 94:607-618. https://doi.org/10.1016/j. carbon.2015.07.026

Xie T, Dong J, Chen H, Jiang Y, Yao Y (2016) Experimental investigation of deicing characteristics using hot air as heat source. Applied Thermal Engineering 107:681-688. https://doi.org/10.1016/j.applthermaleng.2016.05.162

Yang Y, Boom R, Irion B, van Heerden DJ, Kuiper P, Wit H (2012) Recycling of composite materials. Chemical Engineering and Processing: Process Intensification 51:53-68. https://doi.org/10.1016/i.cep.2011.09.007

Yao X, Falzon BG, Hawkins SC, Tsantzalis S (2018) Aligned carbon nanotube webs embedded in a composite laminate: a route towards a highly tunable electro-thermal system. Carbon 129:486-494. https://doi.org/10.1016/i.carbon.2017.12.045

Yi JY, Choi GM (1999) Percolation behavior of conductor-insulator composites with varying aspect ratio of conductive fiber. Journal of electroceramics 3(4):361-369. https://doi.org/10.1023/A:1009913913732

Yin Y, Mays TJ, McEnaney B (1989) The measurement of grain orientations in an extruded electrode graphite using image analysis. Carbon 27(1):113-115. https://doi.org/10.1016/0008-6223(89)90163-2

Zhang B, Soltani SA, Le LN, Asmatulu R (2017a) Fabrication and assessment of a thin flexible surface coating made of pristine graphene for lightning strike protection. Materials Science and Engineering: B 216:31-40. https://doi.org/10.1016/j.mseb.2017.02.008

Zhang Z, Chen B, Lu C, Wu H, Wu H, Jiang S, Chai G (2017b) A novel thermo-mechanical anti-icing/de-icing system using bi-stable laminate composite structures with super hydrophobic surface. Composite Structures 180:933-943. https://doi.org/10.1016/j.compstruct.2017.08.068

Zhang Z, Li Y, Wu H, Zhang H, Wu H, Jiang S, Chai G (2018a) Mechanical analysis of functionally graded graphene oxide-reinforced composite beams based on the first-order shear deformation theory. Mechanics of Advanced Materials and Structures 1-9. https://doi.org/10.1080/15 376494.2018.1444216

Zhang Z, Li Y, Wu H, Chen D, Yang J, Wu H, Jiang S, Chai G (2018b) Viscoelastic bistable behaviour of antisymmetric laminated composite shells with time-temperature dependent properties. Thin-walled Structures 122:403-415. https://doi.org/10.1016/j.tws.2017.10.036 
Zhang Z, Pan H, Wu H, Jiang S, Chai G (2018c) Hygroscopic influence on bistable characteristics of antisymmetric composite cylindrical shells: An experimental study. Journal of Composite Materials 52(26):3565-3577. https://doi.org/10.1177/0021998318766226

Zhang Z, Wu H, Ye G, Wu H, He X, Chai G (2014) Systematic experimental and numerical study of bistable snap processes for anti-symmetric cylindrical shells. Composite Structures, 112:368-377. https://doi.org/10.1016/i.compstruct.2014.02.030

Zhang ZJ, Sima WX, Jiang XL, Sun CX, Shu LC (2005) Study on the lightning protection performance of shielding failure for UHV\&EHV transmission lines. Proceedings of the Chinese Society of Electrical Engineering 25(10):1-6.

Zhao J-X (2003) Application of carbon composite materials for civil aviation [J]. Hi-tech Fiber \& Application 3.

Zhao H, Wu Z, Wang S, Zheng J, Che G (2011) Concrete pavement deicing with carbon fiber heating wires. Cold Regions Science and Technology 65(3):413-420. https://doi.org/10.1016/j.coldregions.2010.10.010

Zimmerli B, Strub M, Jeger F, Stadler O, Lussi A (2010) Composite materials: composition, properties and clinical applications. A literature review. Schweizer Monatsschrift fur Zahnmedizin 120(11):972-986. 